This item was submitted to Loughborough's Research Repository by the author.

Items in Figshare are protected by copyright, with all rights reserved, unless otherwise indicated.

\title{
Production of polymeric nanoparticles by micromixing in a co-flow microfluidic glass capillary device
}

\section{PLEASE CITE THE PUBLISHED VERSION}

http://dx.doi.org/10.1016/j.cej.2015.05.083

\section{PUBLISHER}

(C) Elsevier

VERSION

AM (Accepted Manuscript)

\section{PUBLISHER STATEMENT}

This work is made available according to the conditions of the Creative Commons Attribution-NonCommercialNoDerivatives 4.0 International (CC BY-NC-ND 4.0) licence. Full details of this licence are available at: https://creativecommons.org/licenses/by-nc-nd/4.0/

\section{LICENCE}

CC BY-NC-ND 4.0

\section{REPOSITORY RECORD}

Othman, Rahimah, Goran T. Vladisavljevic, Hemaka C.H. Bandulasena, and Zoltan K. Nagy. 2015. "Production of Polymeric Nanoparticles by Micromixing in a Co-flow Microfluidic Glass Capillary Device". figshare. https://hdl.handle.net/2134/18323. 


\section{Graphical abstract}
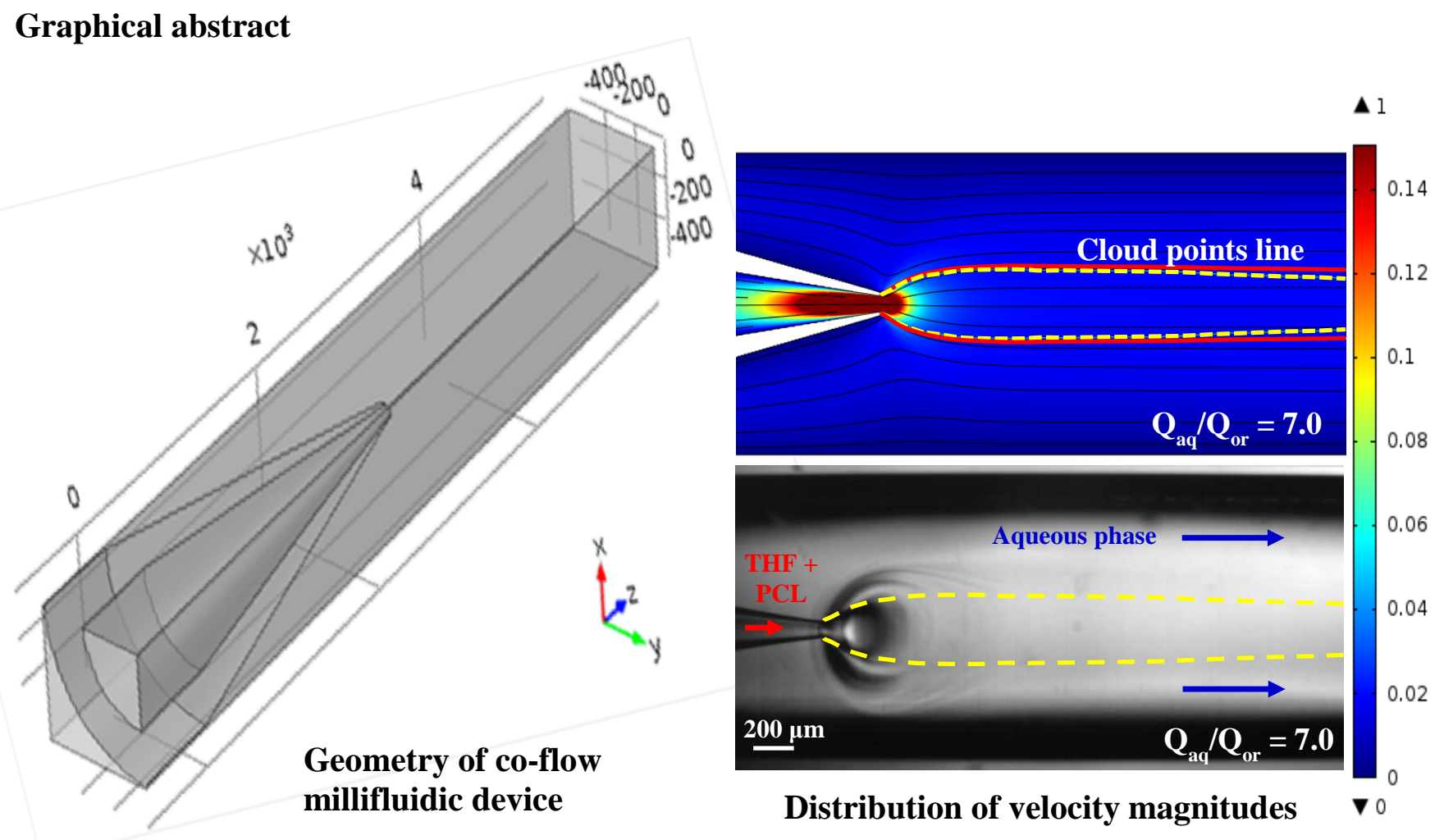
millifluidic device

Distribution of velocity magnitudes

14

12 8

.06 02 


\section{Highlights}

- Micromixing in an axisymmetric (3D) co-flow glass millifluidic device was studied.

- Velocity and concentration fields were simulated and verified experimentally.

- Process was used for production of polymeric nanoparticles by nanoprecipitation.

- The cloud points were predicted from Bagley's two-dimensional solubility graph.

- Particle size decreased with increasing aqueous to organic phase flow rate ratio. 


\title{
Production of polymeric nanoparticles by micromixing in a co-flow glass
}

\section{capillary device}

Rahimah Othman ${ }^{\mathrm{a}, \mathrm{c},{ }^{*}, \text { Goran T. Vladisavljevic }}{ }^{\mathrm{a},{ }^{*}}$, H.C. Hemaka Bandulasena ${ }^{a}$, Zoltan K. Nagy ${ }^{\mathrm{a}, \mathrm{b}}$

${ }^{a}$ Department of Chemical Engineering, Loughborough University, Loughborough, Leicestershire

LE11 $3 T U, U K$

${ }^{b}$ School of Chemical Engineering, Purdue University, West Lafayette, IN 47907-2100, USA

${ }^{c}$ School of Bioprocess Engineering, Universiti Malaysia Perlis, Kompleks Pusat Pengajian

Jejawi 3, 02600 Arau, Perlis, Malaysia

* Corresponding author. Email address: ‥Othman@1boro.ac.uk, G.Vladisavljevic@1boro.ac.uk

\begin{abstract}
Synthetic polymeric biodegradable nanoparticles were produced by micromixing combined with nanoprecipitation in a co-flow glass capillary device consisted of coaxial assembly of glass capillaries, fabricated by aligning a tapered-end round capillary inside a square capillary with 1 $\mathrm{mm}$ internal dimension. Micromixing of water and organic phase (1 wt\% polylactide or polycaprolactone dissolved in tetrahydrofuran) was modelled using a commercial software package Comsol Multiphysics ${ }^{\mathrm{TM}}$ and experimentally investigated using dynamic light scattering, Nanoparticle Tracking Analysis (NTA) and in situ microscopic observation. The organic phase was injected through a nozzle with a diameter of $60 \mu \mathrm{m}$ at the organic-to-aqueous flow-rate ratios ranging from 1.5 to 10 . The locations at which the nanoparticles would form were determined by using the solubility criteria of the polymer and the concentration profiles found by numerical modelling. The convective flux of the polymer in the radial direction was $2-3$ orders of
\end{abstract}


magnitude higher than the diffusive flux of the polymer; hence responsible for mixing the streams. The convective flux near the orifice was 3-4 orders of magnitudes higher than at the end of the computational domain. A maximum convective flux of $0.115 \mathrm{~kg} \mathrm{~m}^{-2} \mathrm{~s}^{-1}$ was found for polycaprolactone at the cloud point for the lowest flow rate ratio investigated. The numerical results were consistent with the experimental observations in terms of flow patterns and mean particle size. Narrower particle size distributions and smaller mean particle sizes were obtained at the higher aqueous-to-organic flow-rate ratios.

Keywords: Computational fluid dynamics; Co-flow glass capillary device; Nanoprecipitation; Nanoparticles; Polylactide; Polycaprolactone.

\section{Introduction}

Advances in microfluidic technology in recent years have provided alternative process strategies in diverse fields, such as materials science, chemical synthesis, biomedical diagnostics and drug screening [1-4]. Compared to conventional macro-scale reaction vessels, test tubes and microtiter plates, microfluidic technology offers many advantages: (i) possibility to use expensive or toxic chemicals due to picolitre fluid volumes; (ii) homogeneous reaction environments due to precise spatial control over process conditions; (iii) ability to continuously and systematically vary reaction conditions; (iv) fast reactions due to high heat and mass transfer

rates as a result of high surface-to-volume ratios; and (v) ability to achieve high levels of parallelisation, integration, and automation of unit operations [5-7].

Although microfluidic techniques are experimentally well-established, optimisation of geometry and operating parameters in microfluidic devices is still challenging [3, 8-9]. Computational fluid dynamics (CFD) has appeared as an effective tool in providing visualized 
information on flow phenomena in complex geometries at both macroscopic and microscopic level $[10,11]$. Yamaguchi et al. [11] applied CFD to simulate laminar co-flow in a microchannel with hairpin bends and the simulation results were consistent with experimental data. Bally et al. [12] performed experiments and CFD simulations to investigate production of methacrylic nanoparticles in a multi-laminating micromixer under different operating conditions. Gradl et al. [13] combined direct numerical simulation with Lagrangian particle tracking to simulate nanoprecipitation in a T-mixer and predict the size distribution of the produced nanoparticles. However, CFD simulations of flow phenomena arising from interaction between miscible liquid streams in microfluidic channels are still lacking. These simulations can provide valuable insight for optimising particle synthesis in two-phase microfluidic and millifluidic devices.

Synthesis of nanoparticles by bulk mixing (conventional method) typically leads to the lack of control over the mixing process, which may compromise the properties of the resulting nanoparticles $[14,15]$. Bulk mixing is accomplished in two stages, macromixing (mixing at the scale of the whole system driven by convection and turbulent dispersion) and micromixing (mixing at molecular scale governed by Fick's law) [16]. A feature of microfluidic mixers is that the macromixing stage, which is less controllable, can be avoided and mixing can be accomplished solely by molecular diffusion. Microfluidic mixing processes can be divided into active and passive strategies. Active mixing is based on providing an external source of energy to enhance mixing such as electric field or ultrasound, whereas passive mixing is any technique that requires no additional energy input, other than energy existing in the fluid flow. This study deals with passive microfluidic mixing that takes advantage of small lateral dimensions of microfluidic channels, which dramatically increase the effect of diffusion [17-19]. 
Nanoprecipitation triggered by passive microfluidic mixing has been used to synthesise various nano-sized products, such as liposomes [20-23], solid lipid nanoparticles [24, 25], micelles [26], chitosan nanoparticles [27], nanocrystals [28, 29], and drug nanoparticles [30-32]. Nanoprecipitation requires two miscible solvents, but both the excipient and active ingredient (e.g. a drug) must be soluble in only one of them. The process is associated with a rapid selfassembly of macromolecules into nanoparticles occurring when a macromolecular excipient solution is added to a non-solvent phase, resulting in almost immediate drug entrapment within the nanoparticles $[33,34]$. It is a single-step technique that allows production of nanoparticles from a wide range of preformed polymers $[35,36]$.

Microfluidic devices that have been used in nanoprecipitation processes are flow-focusing devices and microfluidic $\mathrm{Y}$ - and T-junctions. Hydrodynamic flow focusing was used to synthesise PLGA-PEG nanoparticles by rapidly mixing polymer-acetonitrile solution and water [7]. Two lateral water streams were combined with a central organic phase stream and a narrow width of the focused organic stream enabled rapid mixing through diffusion. Y-junction has been used to produce nano-sized drug particles, thereby enhancing bioavailability of poorly watersoluble drugs $[32,37]$. The drug was dissolved in ethanol and then precipitated by mixing the organic phase with a non-solvent (water), which resulted in amorphous spherical particles with a mean size of $500 \mathrm{~nm}$ [32]. T-junction has been used to prepare barium sulphate nanocrystals over a size range of 18-30 $\mathrm{nm}$ and boehmite nanocrystals [38].

To the best of our knowledge, this work is the first computational and experimental study dealing with the formation of poly (lactic acid) (PLA) and polycaprolactone (PCL) nanoparticles by nanoprecipitation in a co-flow glass capillary device [39-41]. Glass capillary devices have been mainly used for preparation of emulsions, emulsion-templated microparticles, and vesicles 
such as polymersomes, colloidosomes and liposomes [39, 40, 42-44]. Recently, glass capillary devices have been used for fabrication of liposomes with a mean vesicle size in the range of 73$131 \mathrm{~nm}$ [45]. Compared to planar flow focusing polydimethylsiloxane (PDMS) microfluidic devices more often used in nanoprecipitation, glass capillary devices offer several advantages: (i) fabrication is cheaper and does not require a master mould; (ii) many solvents commonly used in nanoprecipitation, such as tetrahydrofuran and chlorophorm, swell PDMS to a large extent, whereas glass has excellent chemical resistance against organic solvents; (iii) 3D geometry positions the organic phase at the centre of the collection channel in all directions.

When a 3D orifice is used (Fig. 1b), the organic phase stream is completely surrounded by the aqueous phase and the walls of the collection channel are completely wetted by the aqueous phase. Since the particles are predominantly formed at liquid-liquid interface, which is fully displaced from the channel walls, 3D geometry minimises interaction between the particles and the walls. In a planar geometry (Fig. 1a), the organic phase at the junction is focused in the substrate plane, but not in the vertical axis, which can lead to deposition of the particles on the walls of the collection channel and compromise control over the resultant particle size.

\section{Solubility parameters}

According to the "diffusion-stranding" mechanism, nanoprecipitation is caused by a rapid mutual diffusion of the organic solvent and water, which is accompanied by the diffusion of the polymer from the organic phase towards organic/aqueous phase interface $[46,47]$. The polymer becomes stranded at the organic/aqueous phase interface, due to its low solubility in the aqueous phase. The solubility of polymers in pure solvents and solvent mixtures can be predicted from the Hansen solubility parameters of components involved in the process. 
Hansen divided the Hildebrand solubility parameter, $\delta$, into three components arising from different types of cohesive forces: a dispersion force component, $\delta_{d}$, arising from van der Waals forces, a polar component, $\delta_{p}$, reflecting permanent dipole-permanent dipole forces, and a hydrogen bonding component, $\delta_{h}$, arising from hydrogen bonding [48]. Hansen solubility parameters can be considered as coordinates in a 3D "solubility (Hansen) space" in which all liquid or solid substances may be localised. The more a solvent is close to the polymer in the "Hansen space", the more likely the solvent will be a good solvent for the polymer [48, 49]. Bagley et al. [50] introduced the parameter $\delta_{v}=\left(\delta_{p}{ }^{2}+\delta_{d}{ }^{2}\right)^{1 / 2}$, which led to a 2D graph in which $\delta_{h}$ was plotted against $\delta_{v}$ [51]. It was found that good solvents must be included in the circle of a radius of five $\delta$-units around the polymer [48, 51-53]. Therefore, PLA or PCL are soluble in water-THF mixture if the following condition is satisfied:

$$
5>\sqrt{\left(\delta_{v, M}-\delta_{v, P}\right)^{2}+\left(\delta_{h, M}-\delta_{h, P}\right)^{2}}
$$

where indices $M$ and $P$ denote the solubility parameters of the water-THF mixture and polymer, respectively. The partial solubility parameters of the polymers (PLA and PCL), good solvent (THF) and pure solvent (water) used in this work are listed in Table 1.

The solubility parameters of THF-water mixture can be determined by averaging the solubility parameter values of the individual liquids by volume [56]:

$$
\begin{aligned}
& \delta_{v, M}=\Phi_{W} \delta_{v, W}+\Phi_{T H F} \delta_{v, T F H} \\
& \delta_{p, M}=\Phi_{W} \delta_{p, W}+\Phi_{T H F} \delta_{p, T F H}
\end{aligned}
$$

where $\Phi_{W}$ and $\Phi_{T H F}$ are the volume fractions of water and THF in the solvent mixture.

\section{Experimental}


Co-flow microfluidic mixer used in this work consisted of two coaxial glass capillaries: (i) an inner tapered-end round capillary $(1.15 \mathrm{~mm}$ outer diameter and $650 \mu \mathrm{m}$ inner diameter $)$ and (ii) an outer square capillary (1.15 mm inner dimension). A two-component epoxy glue (Five Minute ${ }^{\circledR}$ Epoxy, ITW Devcon Ltd.) was used to fix the outer capillary onto a glass microscope slide that was used as a platform for the device. The inner capillary was pulled using a P-97 Flaming/Brown micropipette puller (Sutter Instrument Co.) to produce a sharp tip with a small orifice. The inner diameter of the orifice was enlarged to $60 \mu \mathrm{m}$ by sliding the tip against abrasive paper. During this process, the tip was observed with a microforge (Narishige MF-830) microscope. The inner capillary was flushed with water to remove any glass debris and then inserted in the square capillary. The device was placed on the stage of an inverted microscope (XDS-3, GX Microscopes) (Fig. 2a), which was attached to a Phantom V9.0 high-speed camera (Vision Research, Ametek, US). Coaxial alignment of the two capillaries was ensured by measuring the distance from the edge of square capillary to the central axis of the round capillary. It was done by displaying live image from the camera on the computer's screen.

Fig. 2(b) is a schematic view of the device, showing the inner capillary partially inserted into the square capillary. Two syringe needles with plastic hubs were attached to the capillaries to serve as liquid inlets. The needle hub with a single groove was used to deliver organic phase to the opening of the inner capillary. The needle hub with two grooves was used to deliver aqueous phase co-currently through the pockets between the two capillaries (Fig. 2c). The organic phase was $1 \mathrm{mg} \mathrm{ml}^{-1}(1000 \mathrm{ppm})$ solution of PCL or PLA in THF and the aqueous phase was Milli-Q water.

The phase flow rates were controlled by two separate syringe pumps (Harvard Apparatus, model 11 Elite). The organic phase was delivered from a gas-tight syringe via a TFH-resistant 
Teflon tubing (1.59 mm O.D. and $0.8 \mathrm{~mm}$ I.D.). Milli-Q water was delivered from another gas tight syringe via a polyethylene tubing (1.52 $\mathrm{mm}$ O.D. and $0.86 \mathrm{~mm}$ I.D.). The aqueous phase flow rate, $Q_{a q}$, was constant at $5 \mathrm{ml} \mathrm{h}^{-1}$ and the organic phase flow rate, $Q_{o r}$, varied from 3.3 to $0.5 \mathrm{ml} \mathrm{h}^{-1}$. Therefore, the throughput of the NPs was $0.5-3.3 \mathrm{mg} \mathrm{h}^{-1}$.

The mixing process was recorded by the camera at 25 frames per second and $576 \times 288$

resolution. The particle size distribution was measured by dynamic light scattering using Delsa ${ }^{\mathrm{TM}}$ Nano HC particle analyzer (Beckman Coulter, Inc). Nanoparticle tracking analysis (NTA) was performed using a NanoSight LM20 (NanoSight, Amesbury, UK), equipped with a sample chamber with a 642-nm laser. The samples were injected in the sample chamber with sterile syringes (BD Discardit II, New Jersey, USA), and the measurement was performed at room temperature. The Transmission Electron Microscopy (TEM) measurements were carried out using a JEOL JEM-2000 FX transmission electron microscope operated at an accelerating voltage of $200 \mathrm{kV}$. The sample drop was deposited onto a carbon-coated copper mesh and left to dry before being observed. The mesh was coated by dipping it into a suspension of carbon particles in deionised water.

\section{Computational modelling}

The computational domain used for the simulations is shown in Fig. 3. The flow passage created by inserting a round capillary inside a square capillary is not entirely axisymmetric; hence a 3-D domain is required. By considering planes of symmetry, a quarter of the geometry along the axis was used in this numerical study. Sufficient channel lengths upstream and downstream of the nozzle have been selected to avoid inlet and outlet boundaries affecting the flow field and species distribution in the vicinity of the nozzle. The upstream and downstream 
channel lengths from the nozzle for the computational domain were selected to be $2885 \mu \mathrm{m}$ and $3455 \mu \mathrm{m}$ respectively. This selection was confirmed by a preliminary simulation with $50 \%$ longer channels and we found no effect on the dependent variables solved.

The $x$-axis is perpendicular to the walls of the square capillary and equivalent to $y$-axis, due to coaxial alignment of the two capillaries. The $x$ coordinate ranges from $x=0$ at the capillary axes to $x=r$ at the walls of the square capillary, where $r=576 \mu \mathrm{m}$ according to Fig. 2 . The z-axis is oriented in the direction of flow and coincides with the axes of the capillary. $z=0$ corresponds to the orifice outlet position.

\subsection{Governing equations}

The governing equations are the continuity and incompressible Navier-Stokes equations for laminar flow coupled with convection and diffusion equation for species transport. Here, we assume that the transient interfacial tension between the two miscible liquids used in this study is negligible due to similar viscosities and densities. The fluid flow equations were specified as follows:

$$
\begin{aligned}
& \frac{\partial \boldsymbol{\rho}}{\partial t}+\rho \nabla \cdot \boldsymbol{u}=0 \\
& \rho \frac{\partial \boldsymbol{u}}{\partial t}+\rho(\boldsymbol{u} \cdot \nabla) \boldsymbol{u}=\nabla \cdot\left[-p \boldsymbol{I}+\eta\left(\nabla \boldsymbol{u}+\nabla \boldsymbol{u}^{T}\right)\right]
\end{aligned}
$$

where $\boldsymbol{u}, p, I, \rho$ and $\eta$ denotes the velocity field, pressure, identity matrix, density and dynamic viscosity respectively.

The density of THF-water mixture, expressed in $\mathrm{g} \mathrm{cm}^{-3}$, was calculated using the following quadratic polynomial expression [57]: 


$$
\rho=a y^{2}+b y+c
$$

where $y$ is the mass fraction of water in the mixture and $a=-0.1025, b=0.2118$, and $c=0.889$ are constants.

The dynamic viscosity of THF-water mixture, in $\mathrm{mPa}$, was estimated at $293 \mathrm{~K}$ based on the work of [58]:

$$
\eta=\alpha y^{3}+\beta y^{2}+\gamma y+\delta
$$

where $\alpha=-4.4983, \beta=1.9205, \gamma=3.0109, \delta=0.5591$. For pure THF $(y=0), \eta_{T H F}=0.559$ $\mathrm{mPa}$ s. For pure water $(y=1) \eta_{\text {water }}=0.99 \mathrm{mPa} \mathrm{s}$.

The influence of mixture viscosity on the diffusion coefficient of the polymer was taken into account using Wilke-Chang equation $[59,60]$ :

$$
D=\frac{7.4 \times 10^{-8}\left(\xi M_{w}\right)^{\frac{1}{2}} T}{\eta V_{P}^{0.6}}
$$

where $D$ is the diffusion coefficient in $\mathrm{cm}^{2} \mathrm{~s}^{-1}, M_{w}$ is the molecular weight of solvent, $\zeta$ is the association parameter introduced to define the effective molecular weight of the solvent (for nonassociated solvents $\zeta=1$ and for water $\zeta=2.6$ ), $T$ is the absolute temperature, $\eta$ is the dynamic viscosity of the mixture in $\mathrm{mPa} \mathrm{s}$, calculated from Eq. (7), and $V_{P}$ is the molar volume of the polymer at normal boiling point in $\mathrm{cm}^{3} \mathrm{~mol}^{-1}$. The diffusion coefficient was found to be equal to 4.88 and $13.5 \times 10^{-7} \mathrm{~cm}^{2} \mathrm{~s}^{-1}$ for PCL in pure water and pure THF, respectively and 2.24 and 6.20 $\times 10^{-7} \mathrm{~cm}^{2} \mathrm{~s}^{-1}$ for PLA in pure water and THF, respectively.

The convection diffusion equation was solved using Transport of Concentrated Species interface available in Comsol Multiphysics ${ }^{\mathrm{TM}}$. A mixture averaged diffusion model based on 
multicomponent Maxwell-Stefan diffusivities was selected along with convection to solve for species transport:

$$
\frac{\partial\left(\rho \omega_{i}\right)}{\partial t}+\nabla \cdot\left(\rho \omega_{i} \boldsymbol{u}\right)=-\nabla \cdot \boldsymbol{j}_{i}
$$

where $\omega_{i}$ denotes the mass fraction of species $i$ and $\boldsymbol{j}_{i}$ denotes the relative mass flux vector expressed as

$$
\boldsymbol{j}_{i}=-\left(\rho D_{i}^{m} \nabla \omega_{i}+\rho \omega_{i} D_{i}^{m} \frac{\nabla M_{n}}{M_{m}}+D_{i}^{T} \frac{\nabla T}{T}\right)
$$

where $D_{i}^{T}$ is the thermal diffusion coefficient of species $i$ and $D_{i}^{m}$ is the mixture-averaged diffusion coefficient, given by:

$$
D_{i}^{m}=\frac{1-\omega_{i}}{\sum_{k \neq i} \frac{x_{k}}{D_{i k}}}, M_{n}=\left(\sum_{i} \frac{\omega_{i}}{M_{i}}\right)^{-1}
$$

where $D_{i k}$ are the multicomponent Maxwell-Stefan diffusivities, $x_{k}$ is the mole fraction, and $M_{i}$ is the molar mass of component $i$.

\subsection{Boundary conditions}

The boundary conditions for the fluid flow were set as follows: (i) no slip boundary conditions were applied on the walls of both capillaries; (ii) at the inlets, flow velocities and mass fractions for each liquid were set according to the experimental flow rates. The flow was assumed to be fully developed at the orifice and a parabolic profile for the axial velocity, $v_{z}$, was specified; (iii) at the outlet boundary, pressure was set to zero (the solution flows at the outlet of the co-flow device at atmospheric pressure); (iv) axial symmetry conditions were specified where surfaces were created in slicing the geometry. 


\subsection{Numerical method}

The problem was solved using finite element method to predict the flow fields of the organic phase and aqueous phase within the device. A model was developed using Laminar Flow model (for fluid flow) and Transport of Concentrated Species (for convection and diffusion) available in Comsol Multiphysics ${ }^{\mathrm{TM}}$ 5.0. The computational domain was discretised using 2,282,636 tetrahedral mesh elements with a finer mesh closer to the nozzle region. The number of degrees of freedom (DOFs) solved was 2,586,882. Mesh independency of the solution was confirmed by performing computations with a finer mesh of 3,178,218 elements. The variations between solutions for above two meshes were found to be less than $1 \%$ throughout the domain. All the flow rate ratios considered in this study were solved in one simulation using Parametric Sweep feature available under Study Extensions. The total computation time was approximately $135 \mathrm{~min}$ on an Intel Core i7 64-bit $2.7 \mathrm{GHz}$ processor.

Following the simulations, the results were analysed by plotting the nanoprecipitation lines for both PCL and PLA at five different aqueous to organic phase flow rate ratios $\left(Q_{a q} / Q_{o r}=1.5\right.$, 3.0, 4.5, 7.0, and 10.0). The flow rate ratio between the organic phase and aqueous phase was varied using parametric continuation feature available in the package.

\section{Results and Discussion}

\subsection{Bagley's two-dimensional graph for solubility of polymers in THF-water solution}

Figs. 4 (a) and (b) are Bagley's two-dimensional solubility graphs for PCL and PLA, respectively in interaction with pure water, pure THF and water-THF mixtures. As expected, water is located far outside the solubility circle of PCL or PLA, in agreement with the fact that 
water is a non-solvent for both polymers. The position of THF and PCL on the solubility graph in Fig. 4 (a) almost coincides (see also Table 1), indicating that THF and PCL have high affinity for each other and thus, THF is a good solvent for PLA. The THF-water mixtures are all situated on a straight line connecting two pure liquids, at a point corresponding in distance to the volume ratio of the liquids in the mixture. The higher the water content in the mixture, the greater the distance between the mixture and the polymer; hence lower the solubility of the polymer in that mixture. As shown in Fig. 4 (a), a 50/50 THF/water mixture is a poor solvent for PCL since it is located outside the solubility circle, but a solution having 92 vol\% of THF and 8 vol\% of water is a good solvent for PCL. The mixture containing 84 vol\% of THF lies on the solubility circle, which means that nanoprecipitation of PCL starts when the water content in THF-water mixture reaches 16 vol\% (or $18 \mathrm{wt} \%$ ). Fig. 4 (b) shows that nanoprecipitation of PLA starts when the amount of water in THF-water mixture reaches $31 \mathrm{vol} \%$ or $34 \mathrm{wt} \%$. The different positions of PCL and PLA on the solubility graph reflect the fact that the polarity of PLA is higher than that of PCL, as can be seen from corresponding $\delta_{p}$ values in Table 1 . The polarity of PLA and PCL is due to their polar ester groups, but PCL is more hydrophobic than PLA because it contains a longer hydrocarbon chain on each side of the ester group $\left(-\left(\mathrm{CH}_{2}\right)_{5}-\right.$ as compared to $\left.-\mathrm{CH}\left(\mathrm{CH}_{3}\right)-\right)$.

\subsection{Numerical simulation of two phase co-flow}

The distribution of flow velocities and concentrations in a microfluidic mixer depends on geometry of the device, physical and thermodynamic properties of the ternary system (polymerwater-THF), such as polymer solubility, diffusion coefficients, viscosity and density of the mixture, interfacial tension, and operating conditions (flow rates of the aqueous and organic phase and the flow rate ratio). In this work, the Korteweg stress contribution at the mixing region 
separating the two fluids is not accounted for due to similar viscosities and densities of the fluids used. The contribution of Korteweg stress term is proportional to the viscosity contrast of the two miscible fluids; hence advection arising from this term is negligible for low viscosity ratios [61].

\subsubsection{Distribution of flow velocities in the co-flow microfluidic device}

Fig. 5 shows velocity magnitude at a constant aqueous phase flow rate of $Q_{a q}=5 \mathrm{ml} \mathrm{h}^{-1}$ and at five different organic phase flow rates, $Q_{o r}\left(0.5,3.0,4.5,7.0\right.$, and $\left.10.0 \mathrm{ml} \mathrm{h}^{-1}\right)$. The colour bar on the right side of the figure represents normalised velocity magnitude within the computational domain. The precipitation lines for PLA and PCL calculated from Bagley's solubility criteria are shown in the figure as solid red (PLA) and yellow (PCL) dashed lines, respectively. The polymers start to precipitate when they reach the respecting precipitation line during diffusion and convection in the radial direction.

A flow space downstream of the nozzle can be divided into two distinct regions separated by the precipitation lines: an unsaturated region located between the two precipitation (cloud point) lines, where a polymer is fully soluble in the liquid phase due to high concentration of THF and a supersaturated region situated between the precipitation lines and the wall of the collection capillary, where the polymer is insoluble and forms nanoparticles. As can be seen in Fig. 5, the unsaturated region is narrower for PCL than PLA, because PCL is less soluble in water and starts precipitating at the higher THF concentration compared to PLA.

The average velocity of the organic phase emerging from the nozzle is given by: $U_{N, o r}=4 Q_{o r} /\left(\pi D_{N}^{2}\right)$, where $D_{N}$ is the inner diameter of the nozzle. For the conditions shown in

Fig. 5, the average velocity of the organic phase in the nozzle ranged from $0.05 \mathrm{~m} \mathrm{~s}^{-1}$ at $Q_{o r}=0.5$ $\mathrm{ml} \mathrm{h}^{-1}$ to $0.32 \mathrm{~m} \mathrm{~s}^{-1}$ at $Q_{o r}=3.3 \mathrm{ml} \mathrm{h}^{-1}$. The average velocity of the aqueous phase at nozzle is 
given by: $U_{N, a q}=Q_{a q} /\left[a^{2}-\left(D_{o}^{2} \pi / 4\right)\right]$, where $D_{o}$ is the outer diameter of the nozzle and $a$ is the inner dimension of the square capillary. For the conditions shown in Fig. 5, the average velocity of the aqueous phase at the injection point, $U_{N, a q}=0.001 \mathrm{~m} \mathrm{~s}^{-1}$, is much lower than that of the organic phase, $U_{N, o r}=0.05 \mathrm{~m} \mathrm{~s}^{-1}$. As a result of the large difference in velocity between the two streams, momentum is exchanged between the fluid streams until a steady-state parabolic velocity profile is established downstream of the nozzle. According to Fig. 5, the region where velocity exceeds $90 \%$ of the maximum velocity (represented by dark red colour) extends approximately 7 nozzle diameters downstream at $Q_{o r}=3.3 \mathrm{ml} \mathrm{h}^{-1}$, but is limited to approximately 2 nozzle diameters at $Q_{o r}=0.5 \mathrm{ml} \mathrm{h}^{-1}$. Also this high-velocity region changes its shape from an elongated ellipse at high $Q_{o r}$ values to a semi-sphere at low $Q_{o r}$ values. At the organic phase flow rates of 3.3 and $1.7 \mathrm{ml} \mathrm{h}^{-1}$, vortices are formed in the aqueous phase near the nozzle (Figs. 5 (a) and 5 (b)), due to the large difference in velocity between the organic and aqueous phase. It is possible that nanoparticles formed near the nozzle in these cases be trapped within vortices and forced into circular motion instead of being immediately swept away, which may lead to much longer residence time of these particles compared to the ones formed further downstream. As a result of non-uniform residence time of particles in the device, a broader particle size distribution can be expected for higher organic flow rates (Fig. 5(a) and 5(b)) compared to low organic flow rates shown in Fig. 5 (c) to 5 (e), where vortices are absent.

At $Q_{o r}=3.3 \mathrm{ml} \mathrm{h}^{-1}$ (Fig. 5 (a)), the unsaturated (solvent-rich) region is narrow near the nozzle and reaches a maximum thickness of $28 D_{N}$ downstream of the nozzle. This reflects the fact that the organic phase emerges from the nozzle at a relatively high velocity and a considerable distance is required for the velocities of the two phases to equilibrate. Once the 
maximum thickness is established, the unsaturated region remains unchanged until the end of the computational domain. At this point, mixing occurs mainly by diffusion in radial direction, therefore the effect of mixing is not visible. The mean residence time of fluid elements downstream the nozzle is inversely proportional to the total flow rate $\left(Q_{o r}+Q_{a q}\right)$. At $Q_{o r}=0.5$ $\mathrm{ml} \mathrm{h}^{-1}$ (Fig. 5e), a maximum thickness of the unsaturated region is $\sim 5 D_{N}$ and the organic phase velocity is quickly reduced to the equilibrium value. Since the fluid elements have $50 \%$ longer mean residence time in Fig. 5 (e) than in Fig. 5 (a), the effect of mixing on the shape of the precipitation lines is clear and the unsaturated region is narrower at the end of the computational domain. It can be explained by the progressive replacement of organic phase by water through the interfacial area, leading to shrinkage of the unsaturated region. At a sufficiently long distance downstream of the nozzle, the two precipitation lines will join together at the central axis, which means that the supersaturated region will occupy the entire cross section of the collection capillary.

Fig. 6 shows velocity profiles at a cross-section one nozzle diameter downstream of the nozzle for the five different flow rate ratios. As shown in Fig. 6 (a), the axial velocity $\left(U_{z}\right)$ for all flow rate ratios decreases from a maximum value at the central axis $(x=0)$ to zero at the wall $(x=576)$ of the capillary. A maximum axial velocity of $0.44 \mathrm{~m} \mathrm{~s}^{-1}$ was found for the lowest flow rate ratio $(\mathrm{FR}=1.5)$ while a minimum axial velocity of $0.02 \mathrm{~m} \mathrm{~s}^{-1}$ is recorded for the highest flow rate ratio $(\mathrm{FR}=10)$. These velocities are lower than the maximum axial velocities computed at the nozzle $\left(0.64 \mathrm{~m} \mathrm{~s}^{-1}\right.$ for $\mathrm{FR}=1.5$ and $0.1 \mathrm{~m} \mathrm{~s}^{-1}$ for $\left.\mathrm{FR}=10\right)$ due to viscous dissipation over a distance of $D_{N}$. For the given cross-section, precipitation of PLA or PCL starts $66 \mu \mathrm{m}$ away from the central axis for $F R=1.5$ and the corresponding axial velocity is $0.037 \mathrm{~m} \mathrm{~s}^{-1}$. For $\mathrm{FR}=10$, the polymer precipitation starts at $160 \mu \mathrm{m}$ from the central axis, where $U_{z} \approx 0$. 
Fig. 6 (b) shows profiles of radial velocity $\left(U_{x}\right)$ at a cross-section one nozzle diameter downstream of the nozzle. Negative values of $U_{x}$ represents velocity vectors directed away from the central axis (towards the wall). At $x=0$, the radial velocity is zero for all the flow rate ratios, as no flow across the central axis is possible due to axisymmetric geometry. The radial velocity is negative near the central axis, reflecting the fact that the organic phase stream expands after injection from the nozzle. The highest negative radial velocity is observed at the highest organic phase flow rate. The radial velocity becomes positive farther away from the central axis, since the aqueous phase flows towards the interface. The maximum fluctuation of radial velocity is observed for FR=1.5 due to the vortices formed on either sides of the jet emerging from the nozzle. The radial velocity becomes zero at a distance between 50 and $150 \mu \mathrm{m}$ from the central axis, depending on the flow rate ratio, which roughly corresponds to the position of the interface.

Fig. 7 (a) shows axial velocity profiles $12 D_{N}$ downstream of the nozzle. At $F R=1.5$, the axial velocity at the central axis is $0.018 \mathrm{~m} \mathrm{~s}^{-1}$, which is 5 times greater than the maximum velocity for fully developed laminar flow through a square duct given by: $U_{z, \max }=2.1\left(Q_{a q}+Q_{o r}\right) / a^{2}=0.0036 \mathrm{~m} \mathrm{~s}^{-1}$. Thus, equilibrium velocity profile was not yet established $12 D_{N}$ downstream of the nozzle. Furthermore, due to vortices formed within the aqueous phase, the axial velocity is negative at $x>400 \mu \mathrm{m}$. For $F R=3,4.5,7$ and 10 , the axial velocity profile is parabolic with a maximum velocity at the central axis ranging from 0.0023 to $0.0035 \mathrm{~m} \mathrm{~s}^{-1}$, which is close to $U_{z, \max }$ values for fully developed steady-state laminar flows (0.0024 and $\left.0.0029 \mathrm{~m} \mathrm{~s}^{-1}\right)$ calculated from the above equation. Fig. 7 (b) shows the radial velocity $12 D_{N}$ downstream of the nozzle. Negative values indicate that the flow is diverted away from the central axis. Further down the capillary, fluid flow is fully developed and the radial 
velocity becomes zero. For $F R$ values from 3 to 10, the absolute value of the radial velocities are

less than $0.0005 \mathrm{~m} \mathrm{~s}^{-1}$, which indicates that fully developed velocity profiles are nearly established at 12 nozzle diameters downstream the nozzle. At $F R=1.5$, the radial velocity exceeds $0.004 \mathrm{~m} \mathrm{~s}^{-1}$ at certain locations, indicating that hydrodynamic equilibrium is not yet established.

\subsubsection{Distribution of THF and polymer in the co-flow microfluidic device}

Fig. 8 shows distribution of mass fraction of THF at different flow rate ratios. The boundary between THF and water is very sharp near the nozzle, but becomes blurred farther downstream due to countercurrent mass transfer of THF and water across the interface. At $F R=$ 1.5 , the organic phase flow rate is the highest leading to the thickest organic phase stream and consequently, the longest mixing length. The mixing time is proportional to the square of the width of the organic phase stream and inversely proportional to the diffusivity of THF (Karnik et al., 2008). At $F R=10$, the organic phase stream is so narrow that the mass fraction of THF on the central axis is below 0.9 at the end of the computational domain. At $F R=10$, the organic phase stream is initially very thin, but widens further downstream as a result of its deceleration caused by the interaction with a slow-moving aqueous phase.

Fig. 9 shows profiles of mass fraction of THF at two different cross sections located at $z=D_{N}$ and $z=5 W$ ( $W=$ width of the square capillary). At $z=D_{N}$ (Fig. 9 (a)), the mass fraction of THF in the liquid is 0.99 all the way from the central axis to the interface and then suddenly drops down to zero reflecting the fact that the mixing process has barely begun. However, for $F R$ of 1.5, the mass fraction of THF is not zero between the interface and the wall, due to retention of small amount of THF within the vortices. At $z=5.5 W$ (Fig. 9 (b)), the 
concentration profiles show a gradual variation due to progression of the mixing. When the mixing process is complete, THF will be uniformly distributed over the whole cross section and the concentration profiles will become 'flat' with a mass fraction of THF ranging from 0.37 at $F R=1.5$ to 0.08 at $F R=10$. According to Fig. 9 (b), the mass fraction of THF on the central axis is approximately 0.83 , while the highest concentration was found at $F R=3$. At $F R=1.5$, mixing is enhanced by vortices formed and the concentration of THF is lower on the central axis than that at higher flow rate ratios.

Fig. 10 shows distribution of PCL within the device at different flow rate ratios. Clearly, PCL and THF show similar distribution patterns as mass transfer of both species is governed by similar factors. The total flux of PCL is the sum of diffusive and convective fluxes arising from concentration gradient and bulk fluid motion, respectively. As shown in Table 2, the mass transfer of PCL from the organic phase to the aqueous phase is convection-dominated, since the convective flux is $1-3$ orders of magnitude higher than the diffusive flux. A maximum radial convective flux of $0.115 \mathrm{~kg} \mathrm{~m}^{-2} \mathrm{~s}^{-1}$ was found for PCL at the nozzle for $F R=1.5$. This is caused by vortices formed near the nozzle causing the radial velocity to reach a maximum (Figs. 5 and 6). It is also evident that the convective flux is 3-4 orders of magnitudes higher near the nozzle than that at the end of the computational domain, as the radial velocity is much greater near the nozzle compared to any downstream location. The diffusive flux of PCL follows the same trend with the maximum diffusion rate near the nozzle, due to the largest concentration gradient, as shown in Fig. 9.

\subsubsection{Distribution of dynamic viscosities in the co-flow capillary device}

Fig. 11 shows the variation of dynamic viscosity within the domain at $25{ }^{\circ} \mathrm{C}$. Before mixing the organic phase has a viscosity of $0.559 \mathrm{mPa} \mathrm{s}$ (or $5.59 \mathrm{mP}$ ), while pure water has a 
viscosity of $1 \mathrm{mPa}$. The viscosity of the mixture is higher than that of the feed streams and is given by equation (7). A maximum viscosity of $2.1 \mathrm{mPa}$ s occurs at $\sim 42 \mathrm{wt} \%$ THF while the viscosity at the cloud point is 1.14 and $1.63 \mathrm{mPa}$ s for PCL and PLA, respectively. At $F R=1.5$, radial mass flux near the nozzle is relatively high due to the vortices formed and thus, the viscosity of the mixture is higher in the vicinity of the nozzle than that observed for other flow rate ratios.

\subsection{Experimental validation}

The video recordings of the process captured at $Q_{a q}=5 \mathrm{ml} \mathrm{h}^{-1}$ and $Q_{o r}$ of 0.7 and $3.3 \mathrm{ml} \mathrm{h}^{-1}$ (Figs. 12 a $\&$ b) are in good agreement with the presented numerical simulations. At low $Q_{o r}$ value, the interface is hemispherical and corresponds to the high velocity region shown in Fig. 5 (d). Although the equilibrium interfacial tension between water and THF is zero, a temporary interface is clearly visible, formed due to sharp differences in density and composition when the two liquids are suddenly brought into contact. The formed nanoparticles can be seen in the aqueous phase near the interface. As expected, nanoparticles are not visible between the two cloud point lines due to high THF concentration in this region. Self-assembly of PCL into nanoparticles is almost instantaneous near the nozzle due to high gradients of concentration and high fluxes of PCL, which results in high concentration of nanoparticles in that region. The formation of vortex flow at high $Q_{o r}$ value can be seen in Fig. 12 (b), as predicted in Fig. 5 (a). The interface has a widening shape due to decreasing velocity of the organic phase, as predicted in Fig. 8 (a). As a result of vortex flow, the nanoparticles formed near the nozzle and forced into circular motion, which leads to much longer and non-uniform residence time of these particles compared to the ones formed farther downstream. As a consequence, a broader particle size 
distribution and larger mean particle size was observed at the higher organic flow rate, e.g. at the lower $Q_{a q} / Q_{o r}$ value (Fig. 13a). Furthermore, the particle size distribution was more uniform for microfluidic mixing (Figure 13a) than for bulk mixing (Figure 13b).

Fig. 12 (c) confirms the presence of monodisperse spherical nanoparticles with uniform size distribution at $Q_{a q} / Q_{o r}=10.0$ by tracking individual particles in liquid dispersions. The spherical shape of produced PLA and PCL nanoparticles is clearly visible in the TEM images shown in Figure 14.

\section{Conclusions}

It was demonstrated that a 3-D co-flow microfluidic device constructed by inserting a round capillary inside a square capillary is suitable for fabrication of biodegradable polymeric nanoparticles through anti-solvent nanoprecipitation. Using a two-dimensional $\delta_{h}$ vs. $\delta_{v}$ graph, precipitation of PCL and PLA was found to start when the water content in the organic phase reaches 16 and 31 vol\%, respectively. The organic phase was injected at higher velocities than the aqueous phase to induce radial flow, which led to a significant increase in mass transfer but also in the formation of vortices near the nozzle at the flow rate ratio of 3 or lower.

In general, mass transfer in microfluidic devices is dominated by diffusion. However, for the investigated geometry and operating conditions, it was found that the convective flux of PCL at the cloud point was 1-3 orders of magnitude higher than the diffusive flux in the radial direction. In addition, convective flux of the polymer was 3-4 orders of magnitudes higher near the nozzle compared to the downstream end of the computational domain, which reflects the fact that mixing predominantly occurs in the vicinity of the nozzle. The diffusive flux of the polymer followed the same trend with the maximum rate of molecular diffusion observed near the nozzle due to high concentration gradients. The experimental results are in good agreement with the 
CFD simulation results showing hemispherical interface at low organic phase flow rate and widening jet at high organic phase flow rate. A broader particle size distribution with larger mean particle size was found at higher organic phase flow rate due to longer residence time of nanoparticles as a result of vortex flow.

\section{Acknowledgements}

The authors gratefully acknowledge the financial support given for this work through the Ministry of Higher Education Malaysia. ZK Nagy would like to also acknowledge financial support provided by the European Research Council grant no. [280106-CrySys].

\section{References}

[1] D. Mark, S. Haeberle, G. Roth, F. Von Stetten, R. Zengerle, Microfluidic lab-on-a-chip platforms: requirements, characteristics and applications, Chem. Soc. Rev. 39 (2010) 1153-1182.

[2] H. Song, D.L. Chen, R.F. Ismagilov, Reactions in droplets in microfluidic channels, Angew. Chem. Int. 45 (2006) 7336-7356.

[3] H.A. Stone, A.D. Stroock, A. Ajdari, Engineering flows in small devices: microfluidics toward a lab-on-a-chip, Annu. Rev. Fluid Mech. 36 (2004) 381-411.

[4] S.Y. Teh, R. Lin, L.H. Hung, A.P. Lee, Droplet microfluidics, Lab Chip 8 (2008) 198-220.

[5] A.J. DeMello, Control and detection of chemical reactions in microfluidic systems, Nature 442 (2006) 394-402.

[6] J. deMello, A. deMello, Microscale reactors: nanoscale products, Lab Chip 4 (2004) $11 \mathrm{~N}-15 \mathrm{~N}$.

[7] R. Karnik, F. Gu, P. Basto, C. Cannizzaro, L. Dean, W. Kyei-Manu, R. Langer, O.C. Farokhzad, Microfluidic platform for controlled synthesis of polymeric nanoparticles, Nano Lett. 8 (2008) 2906-2912.

[8] M. Pan, Y. Tang, L. Pan, L. Lu, Optimal design of complex manifold geometries for uniform flow distribution between microchannels, Chem. Eng. J. 137 (2008) 339-346.

[9] O. Tonomura, S. Tanaka, M. Noda, M. Kano, S. Hasebe, I. Hashimoto, CFD-based optimal design of manifold in plate-fin microdevices, Chem. Eng. J. 101 (2004) 397-402.

[10] G.N. Ahuja, A.W. Patwardhan, CFD and experimental studies of solids hold-up distribution and circulation patterns in gas-solid fluidized beds, Chem. Eng. J. 143 (2008) 147-160.

[11] Y. Yamaguchi, F. Takagi, K. Yamashita, H. Nakamura, H. Maeda, K. Sotowa, K. Kusakabe, Y. Yamasaki, S. Morooka, 3-D simulation and visualization of laminar flow in a microchannel with hair-pin curves, AIChE J. 50 (2004) 1530-1535. 
[12] F. Bally, D.K. Garg, C.A. Serra, Y. Hoarau, N. Anton, C. Brochon, D. Parida, T. Vandamme, G. Hadziioannou, Improved size-tunable preparation of polymeric nanoparticles by microfluidic nanoprecipitation, Polym. 53 (2012) 5045-5051.

[13] J. Gradl, H.C. Schwarzer, F. Schwertfirm, M. Manhart, W. Peukert, Precipitation of nanoparticles in a T-mixer: coupling the particle population dynamics with hydrodynamics through direct numerical simulation, Chem. Eng. Process. 45 (2006) 908-916.

[14] J. Baldyga, R. Pohorecki, Turbulent micromixing in chemical reactors - a review, Chem. Eng. J. 58 (1995) 183-195.

[15] J. Pihl, M. Karlsson, D.T. Chiu, Microfluidic technologies in drug discovery, Drug Discov. Today 10 (2005) 1377-1383.

[16] D.S. Chan, D.W. Fuerstnau, Simulation of diffusional mixing of particulate solids by Monte Carlo techniques, Powder Technol. 1 (1967) 174-182.

[17] L. Capretto, W. Cheng, M. Hill, X. Zhang, Micromixing within microfluidic devices, Top. Curr. Chem. 304 (2011) 27-68.

[18] L.E. Locascio, Microfluidic mixing, Anal. Bioanal. Chem. 379 (2004) 325-327.

[19] Z. Zhang, C. Yim, M. Lin, X. Cao, Quantitative characterization of micromixing simulation, Biomicrofluidics 2 (2008) 1-9.

[20] A. Jahn, F. Lucas, R.A. Wepf, P.S. Dittrich, Freezing continuous-flow self-assembly in a microfluidic device: toward imaging of liposome formation, Langmuir 29 (2013) $1717-1723$.

[21] A. Jahn, J.E. Reiner, W.N. Vreeland, D.L. DeVoe, L.E. Locascio, M. Gaitan, Preparation of nanoparticles by continuous-flow microfluidics, J. Nanopart. Res. 10 (2008) 925-934.

[22] A. Jahn, S.M. Stavis, J.S. Hong, W.N. Vreeland, D.L. Devoe, M. Gaitan, Microfluidic mixing and the formation of nanoscale lipid vesicles, ACS Nano. 4 (2010) 2077-2087.

[23] A. Jahn, W.N. Vreeland, M. Gaitan, L.E. Locascio, Controlled vesicle self-assembly in microfluidic channels with hydrodynamic focusing, J. Am. Chem. Soc. 126 (2004) 2674-2675.

[24] N.M. Belliveau, J. Huft, P.J. Lin, S. Chen, A.K. Leung, T.J. Leaver, A.W. Wild, J.B. Lee, R.J. Taylor, Y.K. Tam, C.L. Hansen, P.R. Cullis, Microfluidic synthesis of highly potent limit-size lipid nanoparticles for in vivo delivery of siRNA, Mol. Ther. Nucleic Acids 1 (2012) 1-9.

[25] J. Yun, S. Zhang, S. Shen, Z. Chen, K. Yao, J. Chen, Continuous production of solid lipid nanoparticles by liquid flow-focusing and gas displacing method in microchannels, Chem. Eng. Sci. 64 (2009) 4115-4122.

[26] L .Capretto, S. Mazzitelli, G. Colombo, R. Piva, L. Penolazzi, R. Vecchiatini, X. Zhang, C. Nastruzzi, Production of polymeric micelles by microfluidic technology for combined drug delivery: application to osteogenic differentiation of human periodontal ligament mesenchymal stem cells (hPDLSCs), Int. J. Pharm. 440 (2013) 195-206.

[27] F.S. Majedi, M.M. Hasani-Sadrabadi, S.H. Emami, M. Taghipoor, E. Dashtimoghadam, A. Bertsch, H. Moaddel, P. Renaud, Microfluidic synthesis of chitosan-based nanoparticles for fuel cell applications, Chem. Commun. 48 (2012) 7744-7746.

[28] S. Dev, J. Toster, S. Vadhan Prasanna, M. Fitzgerald, K. Swaminathan Iyer, C.L. Raston, Suppressing regrowth of microfluidic generated drugnanocrystals using polyelectrolyte coatings, RSC Adv. 3 (2013) 695-698. 
[29] V. Génot, S. Desportes, C. Croushore, J.P. Lefèvre, R.B. Pansu, J.A. Delaire, P.R. von Rohr, Synthesis of organic nanoparticles in a 3D flow focusing microreactor, Chem. Eng. J. 161 (2010) 234-239.

[30] H.S.M., Ali, P. York, N. Blagden, Preparation of hydrocortisone nanosuspension through a bottom-up nanoprecipitation technique using microfluidic reactors, Int. J. Pharm. 375 (2009) 107-113.

[31] S. Dev, P. Prabhakaran, L. Filgueira, K.S. Iyer, C.L. Raston, Microfluidic fabrication of cationic curcumin nanoparticles as an anti-cancer agent, Nanoscale 4 (2012) 2575-2579.

[32] H. Zhao, J.X. Wang, Q.A. Wang, J.F. Chen, J. Yun, Controlled liquid antisolvent precipitation of hydrophobic pharmaceutical nanoparticles in a microchannel reactor, Ind. Eng. Chem. Res. 46 (2007) 8229-8235.

[33] H. Fessi, J.P. Devissaguet, F. Puisieux, C. Theis, C. Thies, Process for the preparation of dispersible colloidal systems of a substance in the form of nanoparticles, U.S. Patent 5118 528, Jun 2, 1992.

[34] H. Fessi, F. Puisieux, Nanocapsule formation by interfacial polymer deposition following solvent displacement, Int. J. Pharm. 55 (1989) R1-R4.

[35] U. Bilati, E. Allémann, E. Doelker, Development of a nanoprecipitation method intended for the entrapment of hydrophilic drugs into nanoparticles, Eur. J. Pharm. Sci. 24 (2005) $67-75$.

[36] B.V.N. Nagavarma, K.S.Y. Hemant, A. Ayaz, L.S. Vasudha, H.G. Shivakumar, different techniques for preparation of polymeric nanoparticles - a review, Asian J. Pharm. Clin. Res. 5 (2012) 16-23.

[37] H.S.M. Ali, N. Blagden, P. York, A. Amani, T. Brook, Artificial neural networks modelling the prednisolone nanoprecipitation in microfluidic reactors, Eur. J. Pharm. Sci. 37, (2009) 514-522.

[38] Y. Ying, G. Chen, Y. Zhao, S. Li, Q. Yuan, A high throughput methodology for continuous preparation of monodispersed nanocrystals in microfluidic reactors, Chem. Eng. J. 135 (2008) 209-215.

[39] W.J. Duncanson, T. Lin, A.R. Abate, S. Seiffert, R.K. Shah, D.A. Weitz, Microfluidic synthesis of advanced microparticles for encapsulation and controlled release, Lab Chip 12 (2012) 2135-2145.

[40] W.J. Duncanson, M. Zieringer, O. Wagner, J.N. Wilking, A. Abbaspourrad, R. Haag, D.A. Weitz, Microfluidic synthesis of monodisperse porous microspheres with size-tunable pores, Soft Matter. 8 (2012) 10636-10640.

[41] R.K Shah, H.C. Shum, A.C. Rowat, D. Lee, J.J. Agresti, A.S. Utada, L.Y. Chu, J. W. Kim, A. Fernandez-Nieves, C.J. Martinez, D.A. Weitz, Designer emulsions using microfluidics, Mater. Today 11 (2008) 18-27.

[42] H.C. Shum, D. Lee, I. Yoon, T. Kodger, D.A. Weitz, Double emulsion templated monodisperse phospholipid vesicles, Langmuir 24 (2008) 7651-7653.

[43] G.T. Vladisavljević, W.J. Duncanson, H.C. Shum, D.A. Weitz, Emulsion templating of poly(lactic acid) particles: droplet formation behavior, Langmuir 28 (2012) 12948-12954.

[44] G.T. Vladisavljević, H. Shahmohamadi, D.B. Das, E.E. Ekanem, Z. Tauanov, L. Sharma, Glass capillary microfluidics for production of monodispersed poly (dl-lactic acid) and polycaprolactone microparticles: experiments and numerical simulations, J. Colloid Interface Sci. 418 (2014) 163-170. 
[45] G.T. Vladisavljević, A. Laouini, C. Charcosset, H. Fessi, H.C.H. Bandulasena, R.G. Holdich, Production of liposomes using microengineered membrane and co-flow microfluidic device. Colloids Surf. A doi:10.1016/j.colsurfa.2014.03.016 (2014).

[46] J.T. Davies, K.E. Ridcal, Interfacial Phenomena, second ed., Academic Press, New York, 1963, pp. 343-450.

[47] C.A. Miller, Spontaneous Emulsification Produced by Diffusion - a review, Colloids Surf. $29(1988) 89-102$.

[48] C.M. Hansen, Hansen Solubility Parameters: A User's Handbook, second ed., CRC Press, Boca Raton, 2007.

[49] C. Bordes, V. Fréville, E. Ruffin, P. Marote, J.Y. Gauvrit, S. Briançon, P. Lantéri, Determination of poly(epsilon-caprolactone) solubility parameters: application to solvent substitution in a microencapsulation process, Int. J. Pharm. 383 (2010) 236-243.

[50] E.B. Bagley, T.P. Nelson, J.M. Scigliano, Three-dimensional solubility parameters and their relation to internal pressure measurements in pola and hydrogen bonding solvents, J. Paint Technol. 43 (1971) 35-42.

[51] D.W. Van Krevelen, P.J. Hoftyzer, Properties of Polymers: Their Estimation and Correlation with Chemical Structure, second ed., Elsevier Scientific Publishing Company, Amsterdam-Oxford-New York-Tokyo, 1976.

[52] S.W. Choi, H.Y. Kwon, W.S. Kim, J.H. Kim, Thermodynamic parameters on poly(D,Llactide-co-glycolide) particle size in emulsification-diffusion process, Colloids Surf. A 201, (2002) 283-289.

[53] J.H. Sung, D.C. Lee, Molecular shape of poly(2-ethyl-2-oxazoline) chains in THF, Polym. 42 (2001) 5771-5779.

[54] R.A. Jain, The manufacturing techniques of various drug loaded biodegradable poly(lactide-co-glycolide) (PLGA) devices, Biomaterials 21 (2000) 2475-2490.

[55] Y. Lu, S.C. Chen, Micro and nano-fabrication of biodegradable polymers for drug delivery, Adv. Drug Deliv. Rev. 11 (2004) 1621-1633.

[56] K.W. Suh, D.H. Clarke, Cohesive energy densities of polymers from turbidimetric titrations, J. Polym. Sci. 5 (1967) 1671-1681.

[57] V. Belandria, A.H. Mohammadi, D. Richon, Volumetric properties of the (tetrahydrofuran + water) and (tetra-n-butyl ammonium bromide + water) systems: experimental measurements and correlations, J. Chem. Thermodyn. 41 (2009) 1382-1386.

[58] D. Montgomery, B.O. Heston, F. Blankenship, Evidence of association in the tetrahydrafuran· water system, Proc Okla Acad Sci. (1949) 140-144.

[59] W. Hayduk, H. Laudie, Prediction of diffusion coefficients for nonelectrolytes in dilute aqueous solutions, AIChE J. 20 (1974) 611-615.

[60] C. R. Wilke, P. Chang, Correlation of diffusion coefficients in dilute solutions, AIChE J. 1 (1955) 264-270.

[61] L. Valentini, K.R. Moore, Numerical modeling of the development of small-scale magmatic emulsions by Korteweg stress driven flow, J. Volcanol. Geotherm. Res. 179 (2009) 87-95. 
Table 1. The partial solubility parameters $\left(\delta_{\mathrm{d}}, \delta_{\mathrm{p}}, \delta_{\mathrm{h}}\right.$, and $\left.\delta_{\mathrm{v}}\right)$ of water, tetrahydrofuran (THF), polylactide (PLA), and poly- $\varepsilon$-caprolactone (PCL).

\begin{tabular}{ccccc}
\hline Solubility parameters $\left(\mathrm{J} \mathrm{cm}^{-3}\right)^{1 / 2}$ & Water $^{\mathrm{a}}$ & $\mathrm{THF}^{\mathrm{a}}$ & PLA $^{\mathrm{b}}$ & PCL $^{\mathrm{c}}$ \\
\hline$\delta_{\mathrm{d}}$ & 12.28 & 16.77 & 17.62 & 17.00 \\
$\delta_{\mathrm{p}}$ & 31.30 & 5.71 & 9.70 & 4.80 \\
$\delta_{\mathrm{h}}$ & 34.17 & 7.96 & 11.77 & 8.30 \\
$\delta_{\mathrm{v}}$ & 33.62 & 17.72 & 20.11 & 17.66 \\
\hline
\end{tabular}

a The partial solubility parameters of the solvents taken from Jain [54].

b The partial solubility parameters of PLA calculated based on the classical method for Hansen solubility parameters [55].

c The partial solubility parameters of PCL calculated based on the classical method for Hansen solubility parameters [47].

$\delta$ solubility parameter, subscripts $d$, contribution of the dispersion forces; $p$, polar contribution; $h$, hydrogen bonding contribution; $v$, dispersion and polar contribution. 
Table 2. The radial component of diffusive and convective fluxes of PCL on the cloud line just after the nozzle $(z \rightarrow 0)$ and at the end of the computational domain $\left(z=z_{\max }\right)$ for two different flow rate ratios $(F R=1.5$ and 10$)$.

\begin{tabular}{ccccc}
\hline \multirow{2}{*}{ FR } & \multicolumn{2}{c}{ Diffusive mass flux of PCL / $\mathrm{kg} \mathrm{m}^{-2} \mathrm{~s}^{-1}$} & \multicolumn{2}{c}{ Convective mass flux of PCL / $\mathrm{kg} \mathrm{m}^{-2}$} \\
& $z=0$ & $z=z_{\max }$ & $z=0$ & $z=z_{\max }$ \\
\hline 1.5 & $37 \times 10^{-5}$ & $0.27 \times 10^{-5}$ & $11500 \times 10^{-5}$ & $37 \times 10^{-5}$ \\
10 & $25 \times 10^{-5}$ & $0.047 \times 10^{-5}$ & $1800 \times 10^{-5}$ & $0.11 \times 10^{-5}$ \\
\hline
\end{tabular}




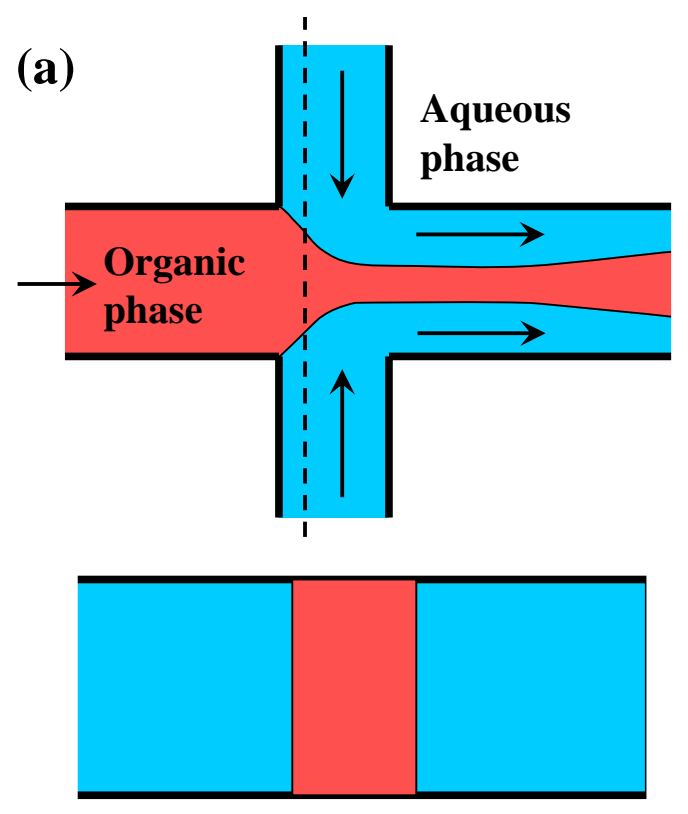

PLANAR (2D) GEOMETRY (b)
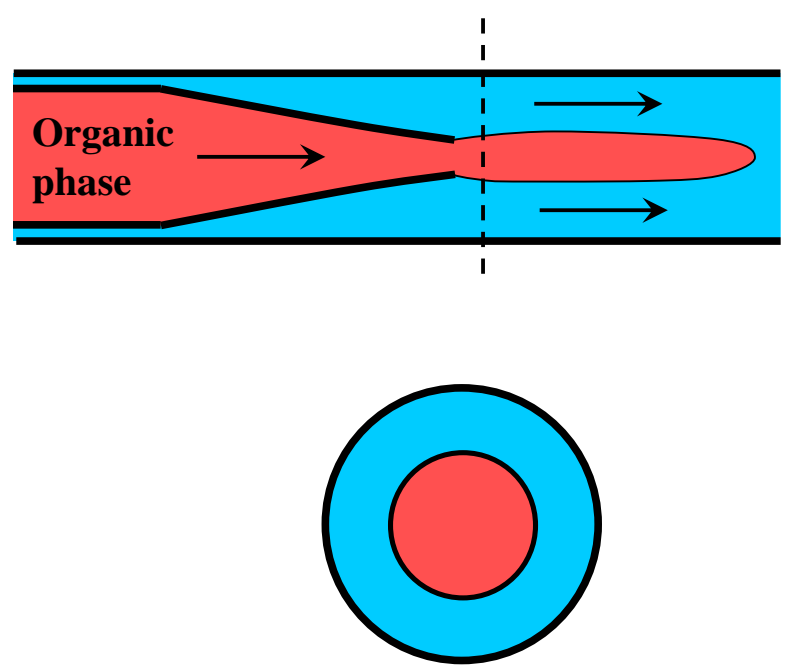

3D GEOMETRY

Fig. 1. Schematic diagram of the top and cross-sectional view of planar (2D) and axisymmetric (3D) co-flow device (- - = cross-sectional line). 
(a)

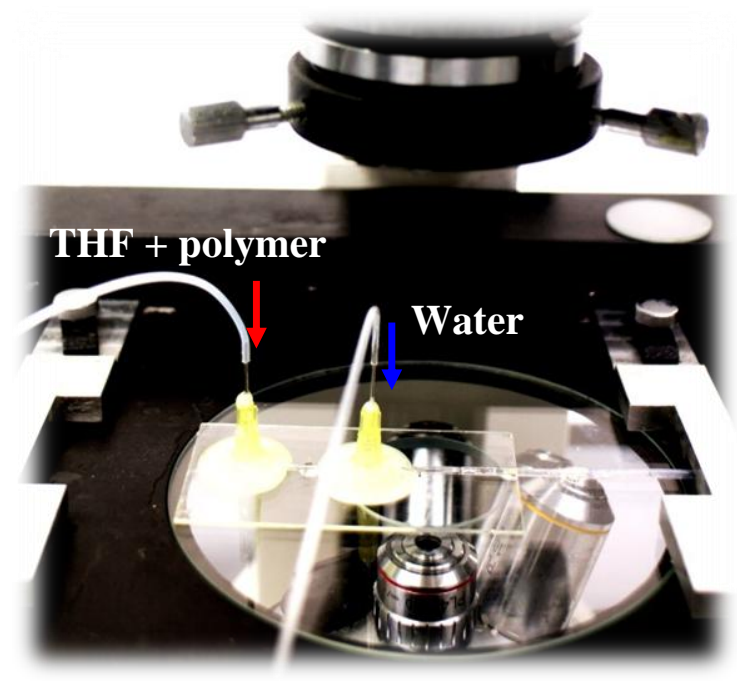

(b)

(c)
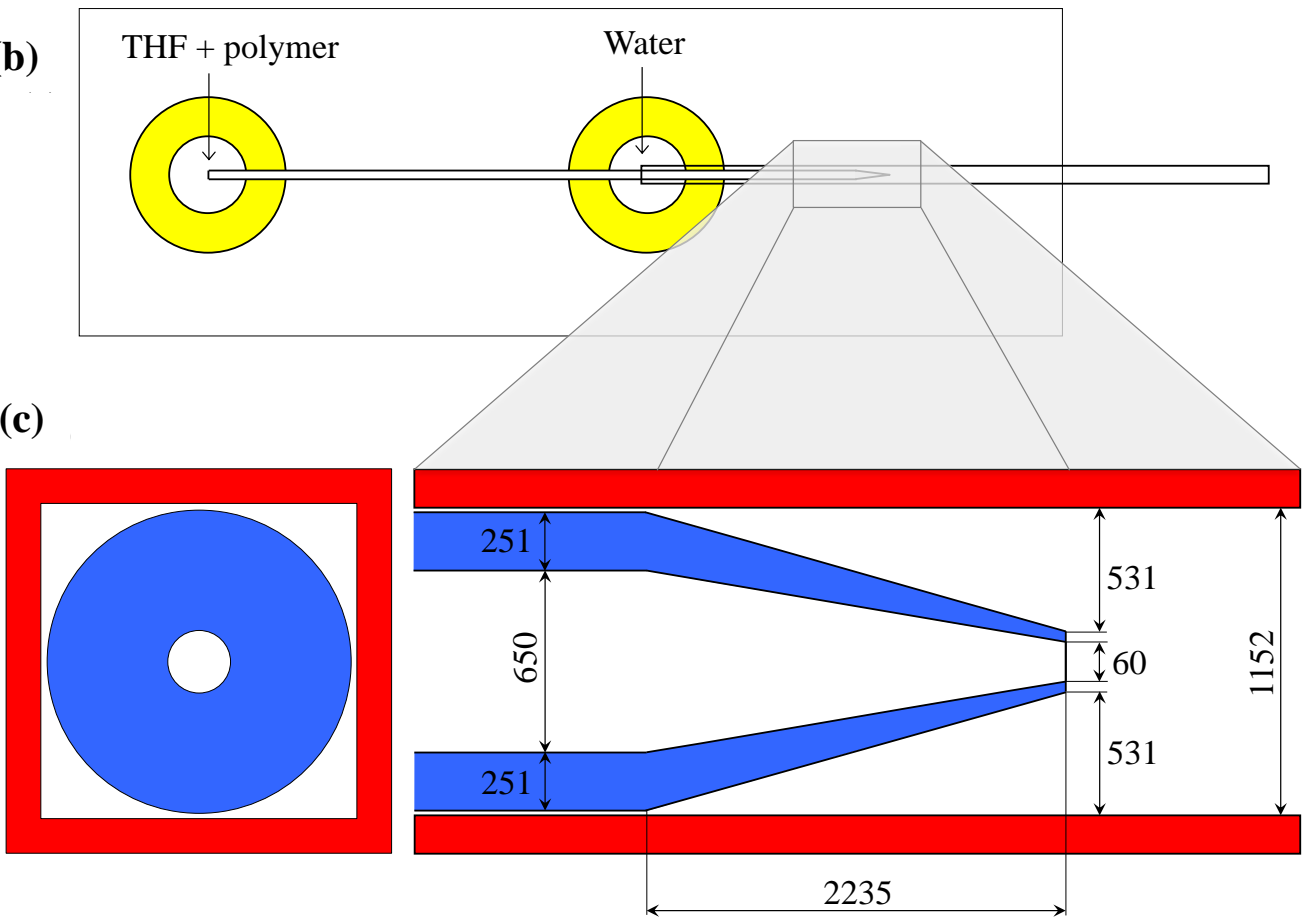

Fig. 2. Geometry of the glass capillary device modelled in this work: (a) A photograph of the experimental equipment; (b) A schematic top view showing coaxial assembly of glass capillaries glued onto a microscope slide. The magnified image is a tapered section of the inner capillary with $60 \mu \mathrm{m}$ diameter orifice; (c) A schematic cross-sectional view showing round inner capillary and square outer capillary. All dimensions are in $\mu \mathrm{m}$. 
Figure 3

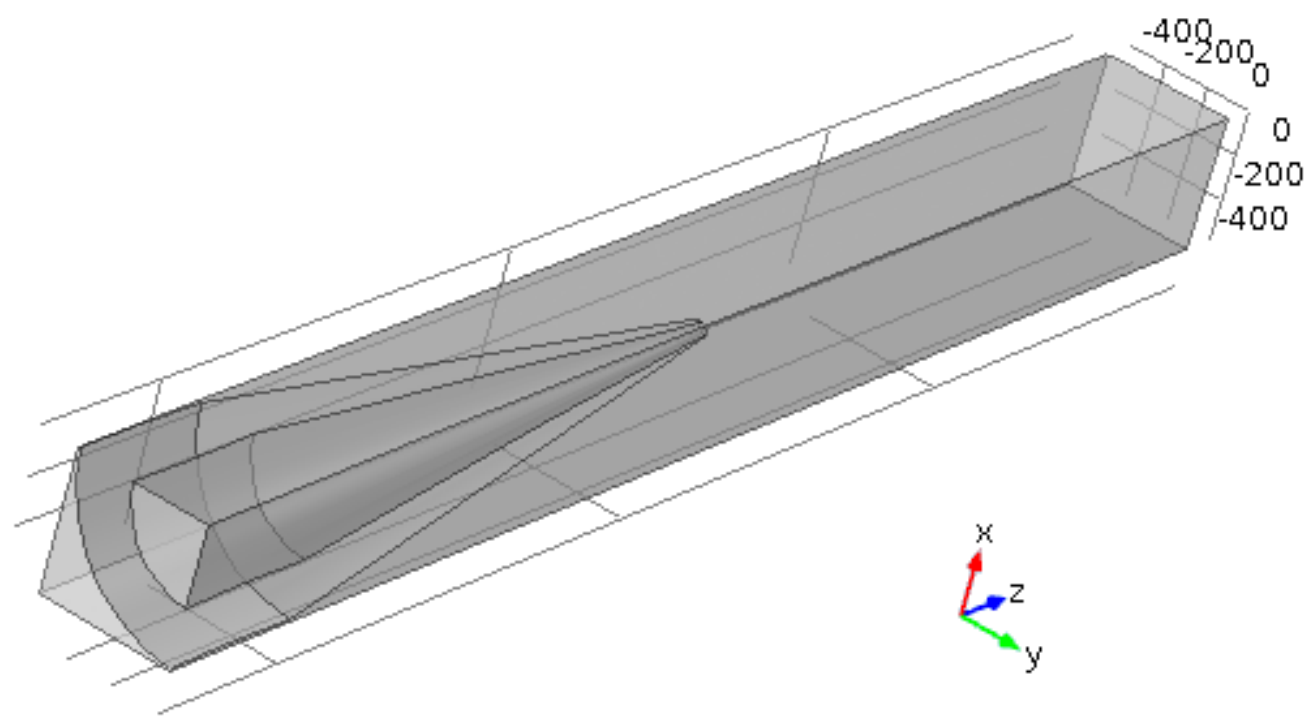

Fig. 3. The model geometry (3-D) of the co-flow microfluidic device. 
(a)

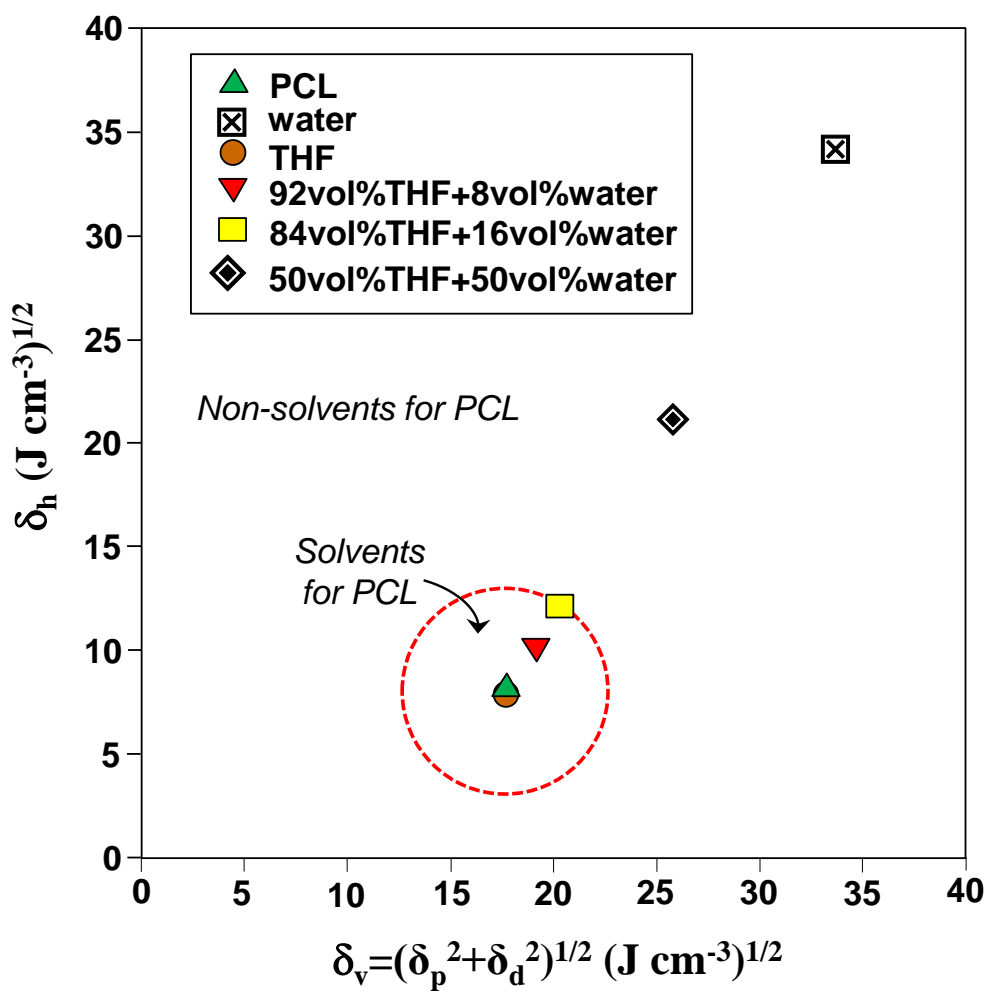

(b)

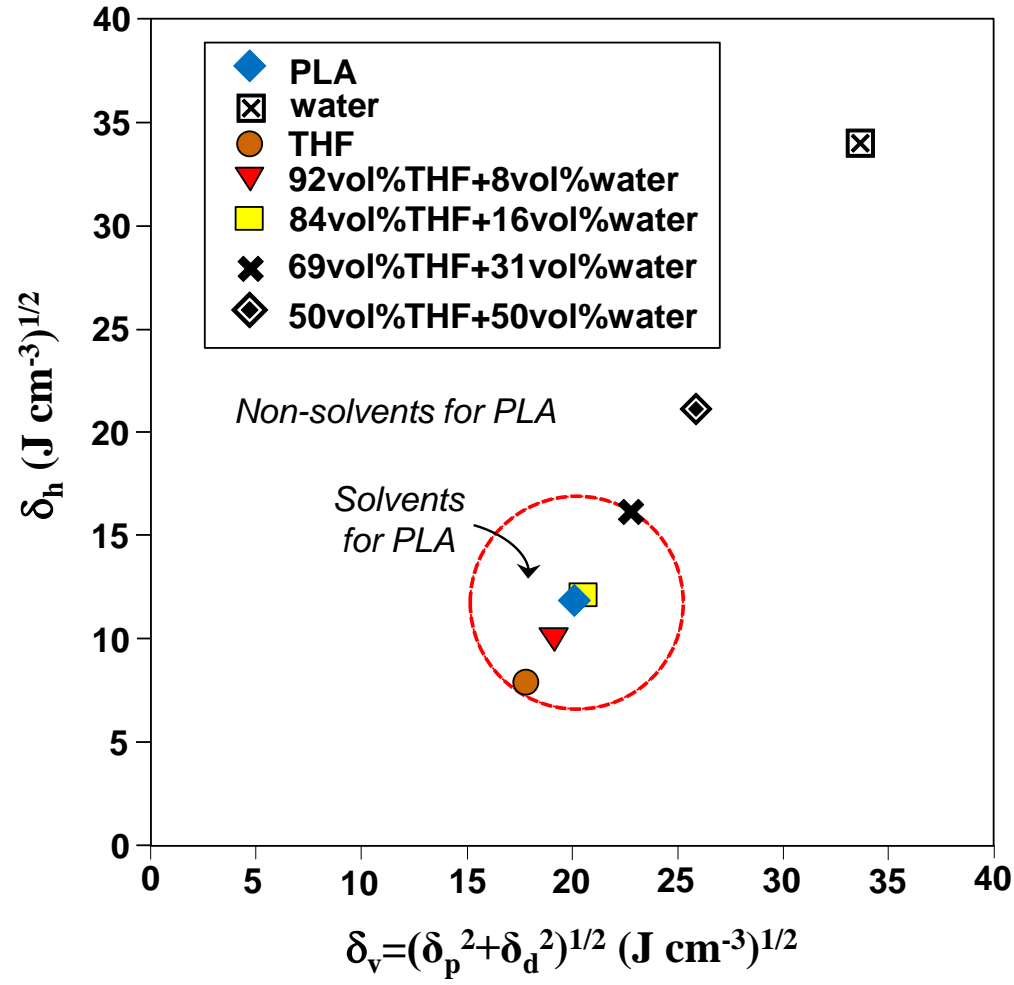

Fig. 4. Bagley's two-dimensional graphs of partial solubility parameters for pure THF, water, and various water-THF mixtures with respect to: (a) PCL; (b) PLA. The solubility circle shown by the red dotted line ( $(\cdots)$ has a radius of $5 \delta$-units and the coordinates of its centre are $\delta_{v}=17.66$ and $\delta_{p}=4.80$ for PCL and $\delta_{v}=20.11$ and $\delta_{p}=9.70$ for PLA. Liquids outside the solubility circle are non-solvents. 
(a)

(b)

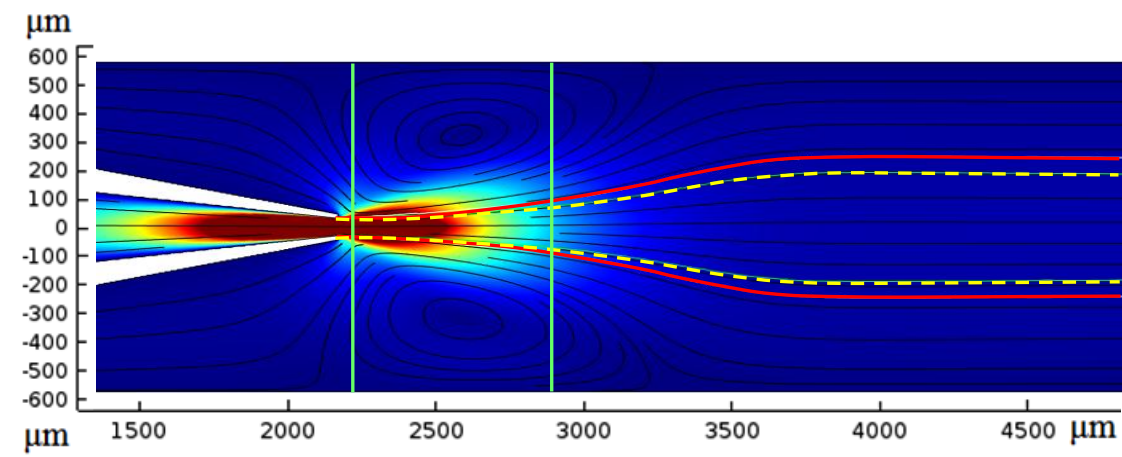

(c)

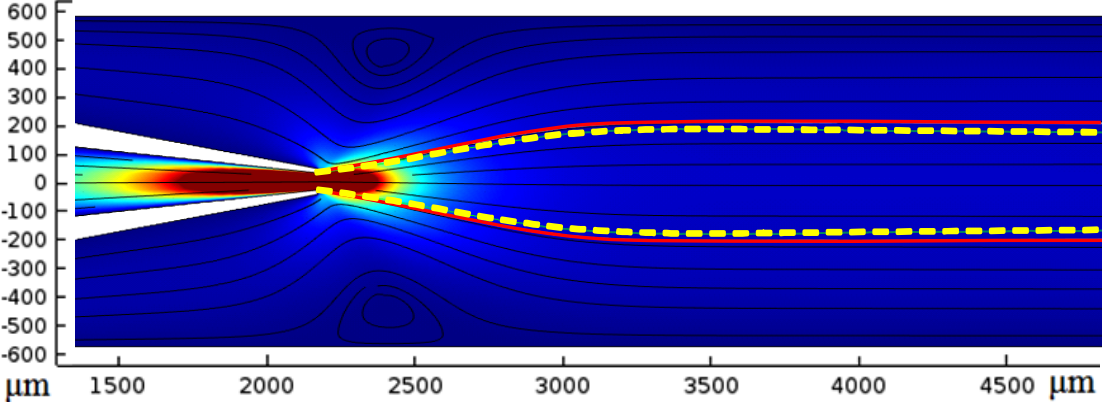

\section{$\Delta 1$}

(d)

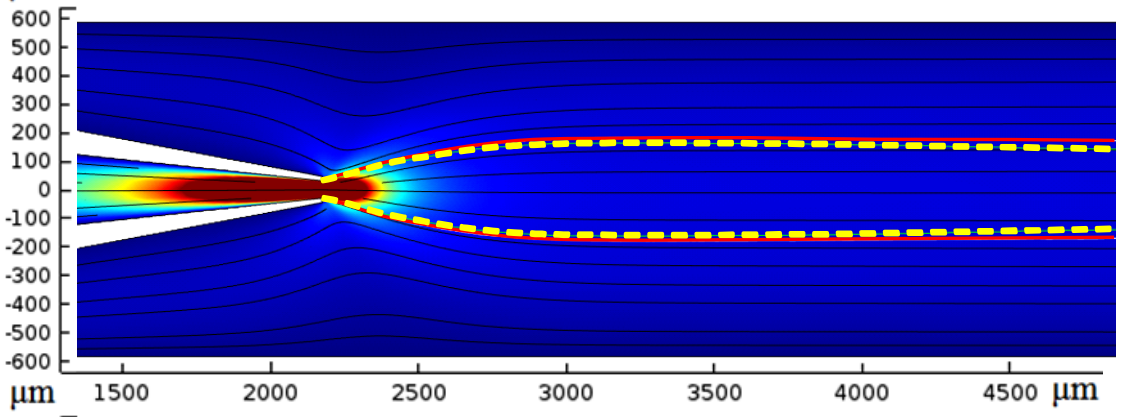

(e)
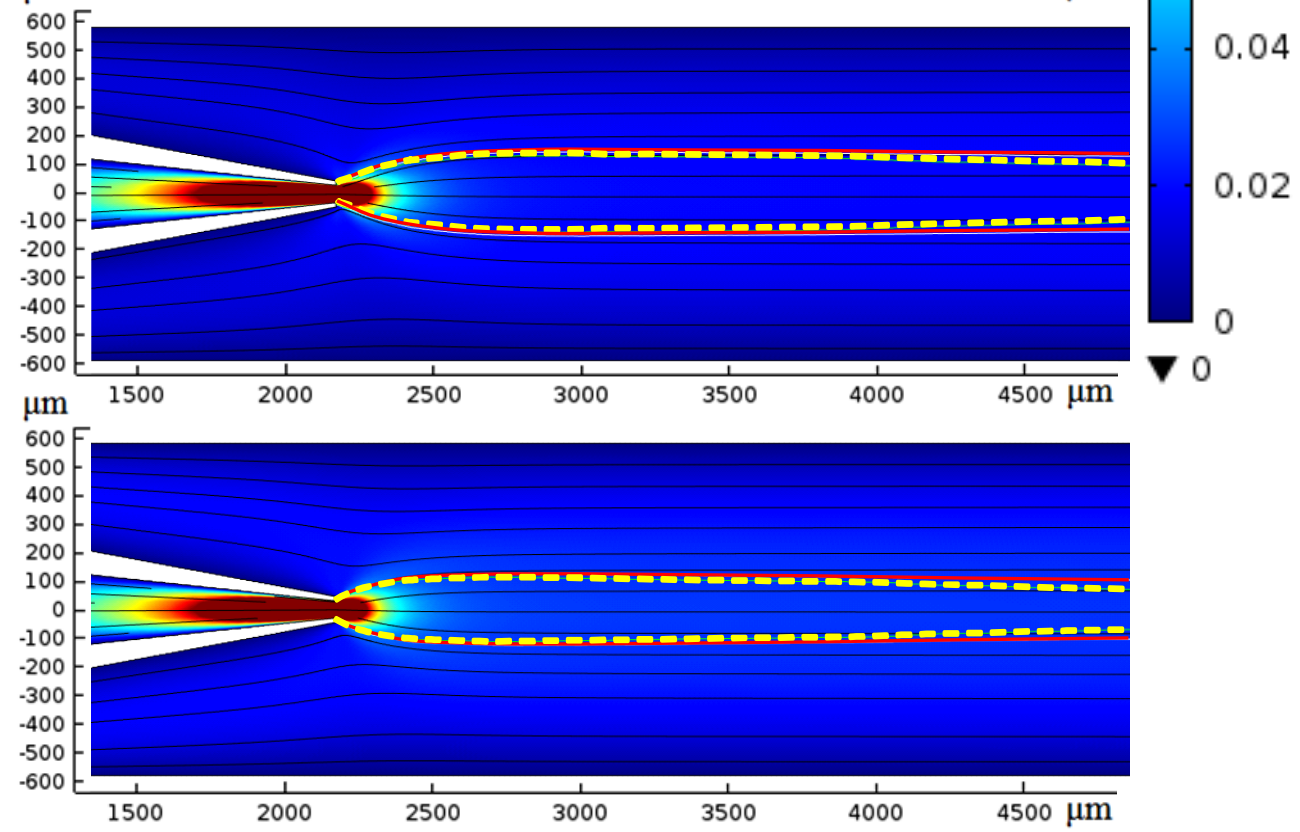

Fig. 5. The distribution of velocity magnitudes at: (a) $Q_{a q} / Q_{o r}=\mathbf{1 . 5}, Q_{a q}=5.0 \mathrm{ml} \mathrm{h}^{-1}, Q_{o r}=$ $3.3 \mathrm{ml} \mathrm{h}^{-1}$; (b) $\boldsymbol{Q}_{a q} / \boldsymbol{Q}_{\boldsymbol{o r}}=\mathbf{3}, Q_{a q}=5.0 \mathrm{ml} \mathrm{h}^{-1}, Q_{o r}=1.7 \mathrm{ml} \mathrm{h}^{-1}$; (c) $\boldsymbol{Q}_{a q} / \boldsymbol{Q}_{o r}=\mathbf{4 . 5}, Q_{a q}=5.0 \mathrm{ml} \mathrm{h}^{-}$ ${ }^{1}, Q_{o r}=1.1 \mathrm{ml} \mathrm{h}^{-1}$; (d) $\boldsymbol{Q}_{a q} / \boldsymbol{Q}_{o r}=7, Q_{a q}=5.0 \mathrm{ml} \mathrm{h}^{-1}, Q_{o r}=0.7 \mathrm{ml} \mathrm{h}^{-1}$; (e) $\boldsymbol{Q}_{a q} / \boldsymbol{Q}_{o r}=\mathbf{1 0}, Q_{a q}=$ $5.0 \mathrm{ml} \mathrm{h}^{-1}, Q_{o r}=0.5 \mathrm{ml} \mathrm{h}^{-1}$. Surface: normalised velocity magnitude. Black contours: stream lines. Solid red lines and yellow dashed lines are the cloud point lines for PLA and PCL, respectively. Vertical green lines in (a) are sections considered in Figures 6 and 7. 
(a)

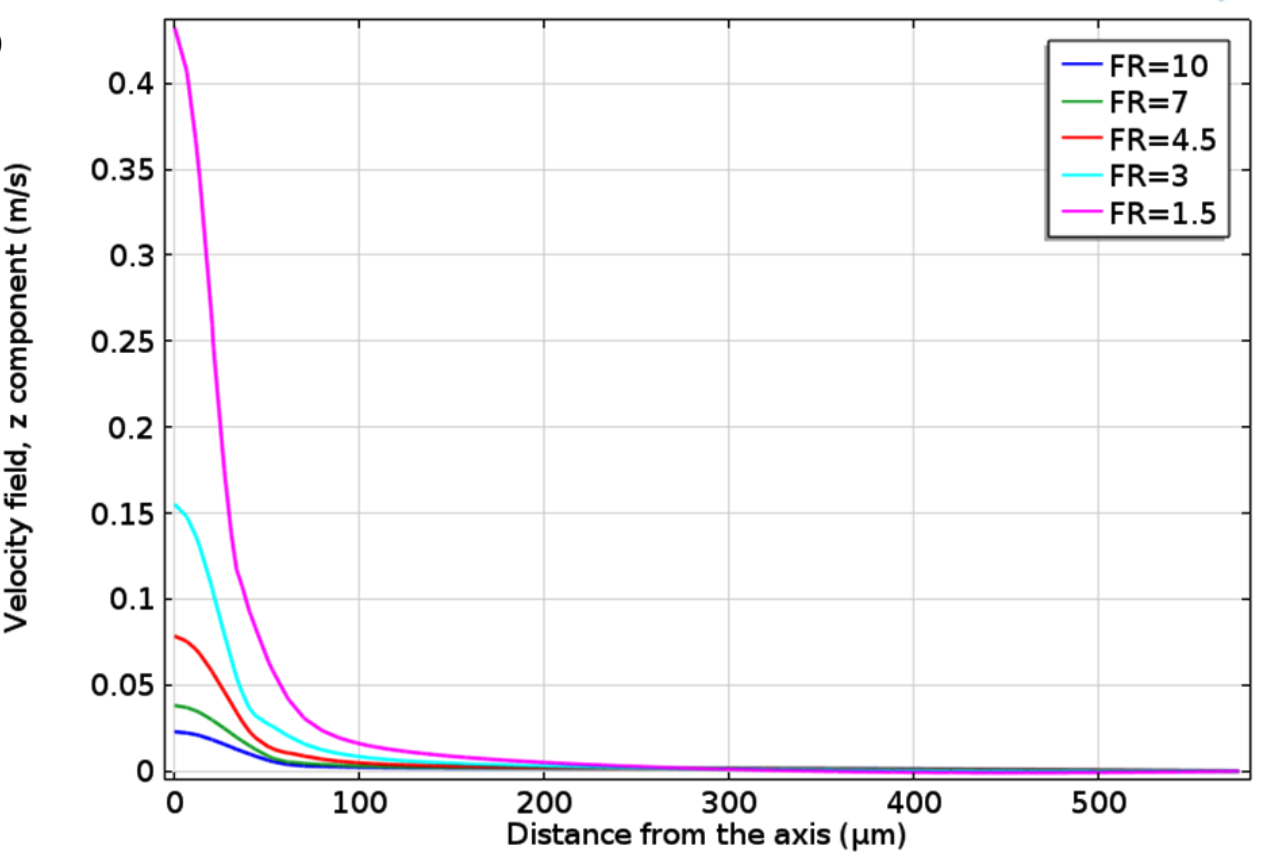

(b)

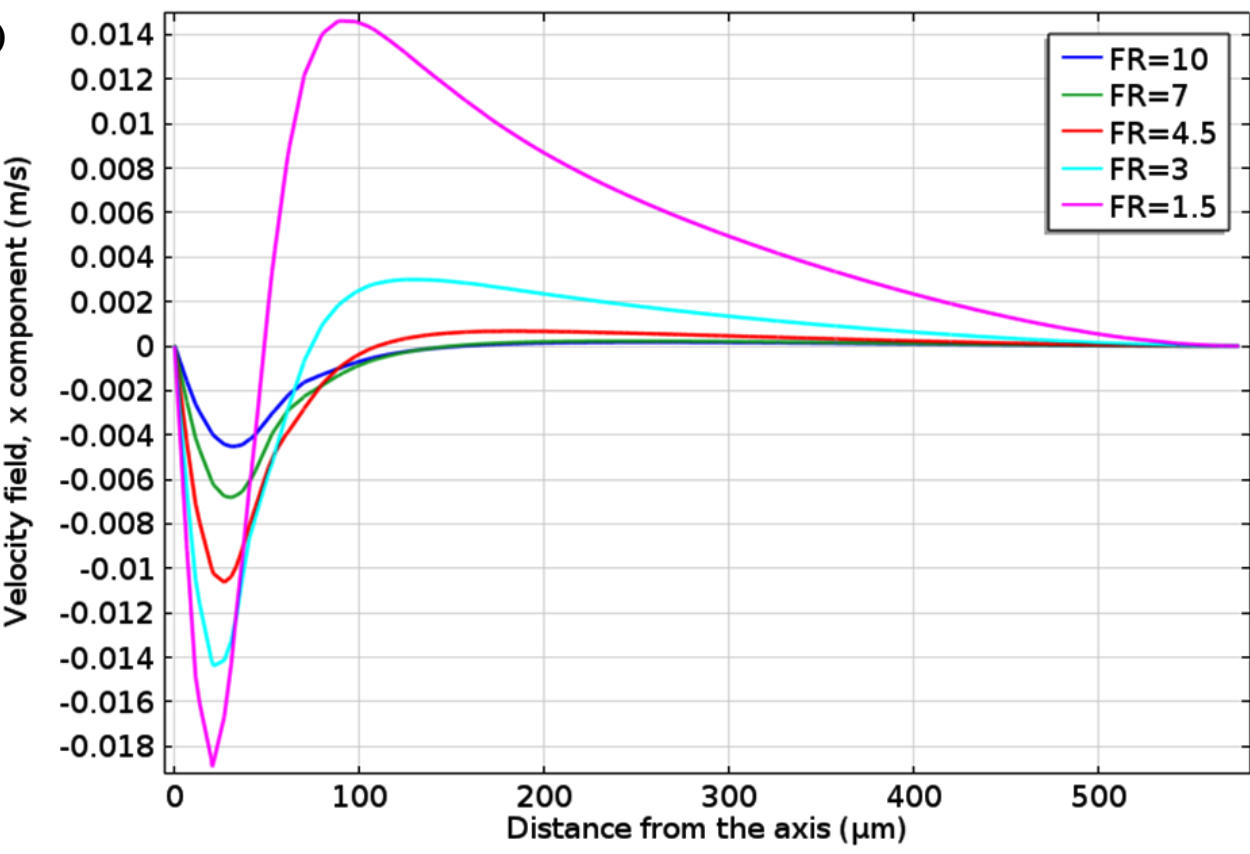

Fig. 6. (a) Axial velocity profiles and (b) radial (along x-axis) velocity profiles at one nozzle diameter downstream of the nozzle for five different flow rate ratios, FR, of the aqueous to organic phase. 

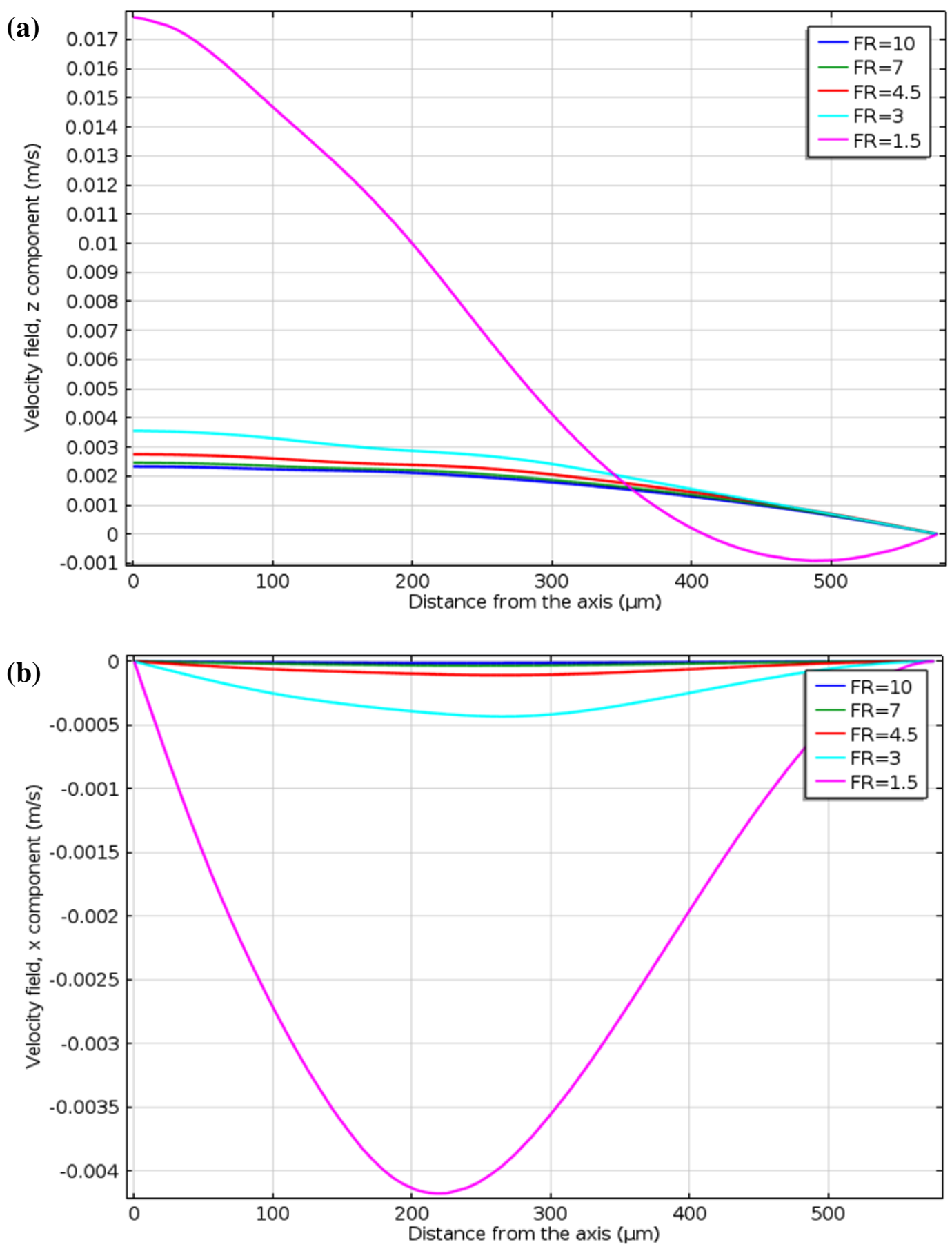

Fig. 7. (a) Axial velocity profiles (along z-axis) and (b) radial velocity profiles (along x-axis) at 12 nozzle diameters downstream the nozzle for five different flow rate ratios (FR). 
(a)

(b)

(c)

(d)
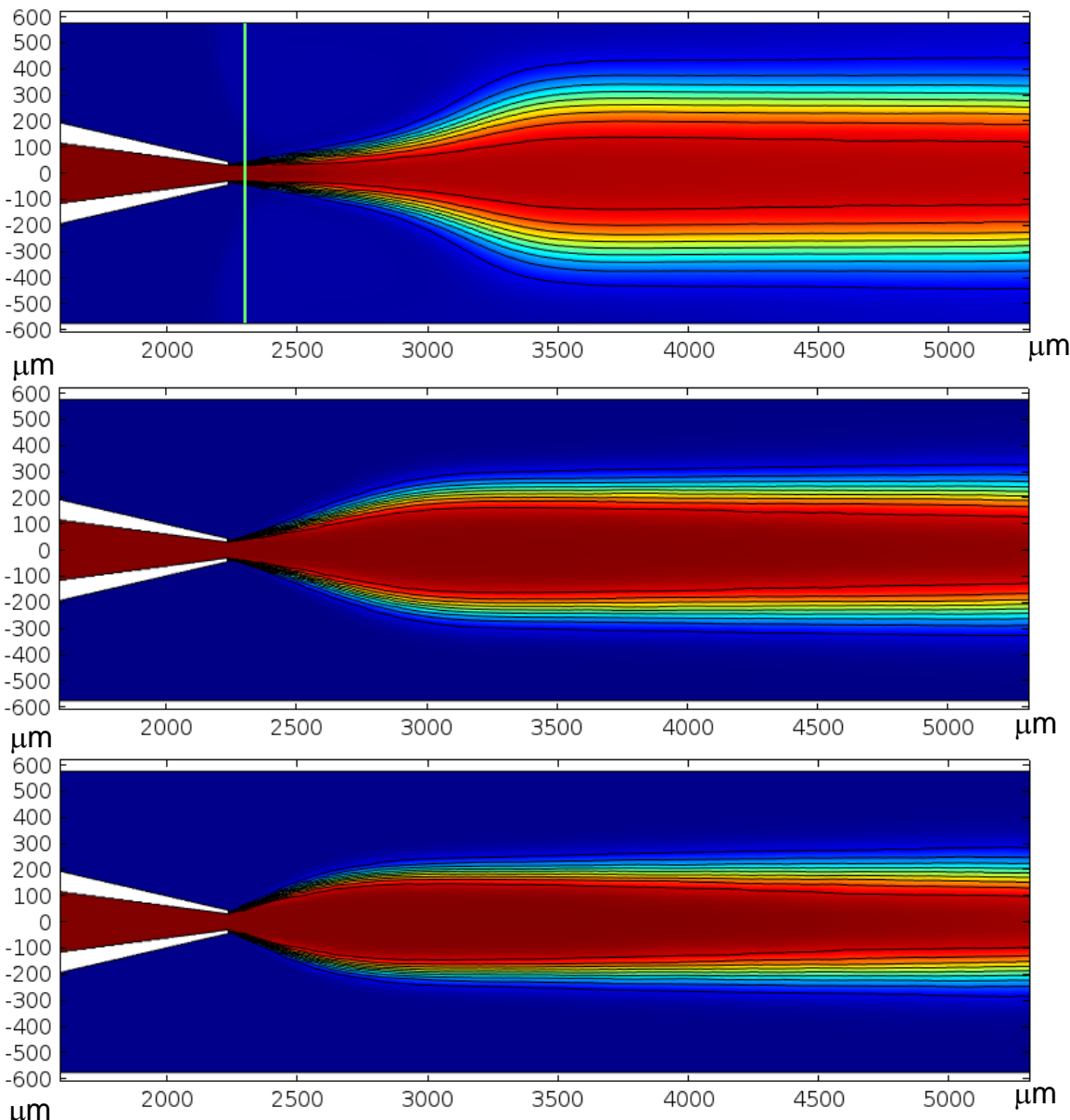

0.7

0.6

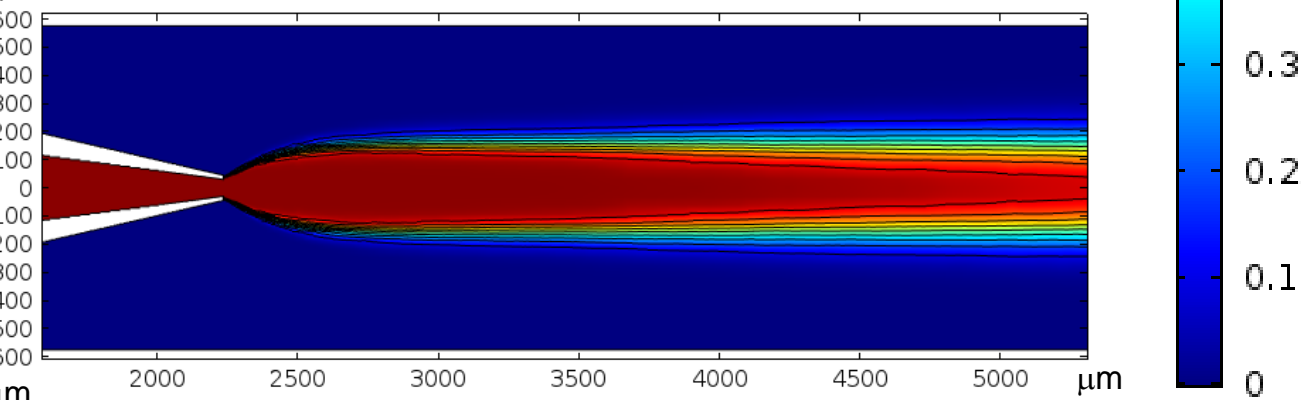

(e)

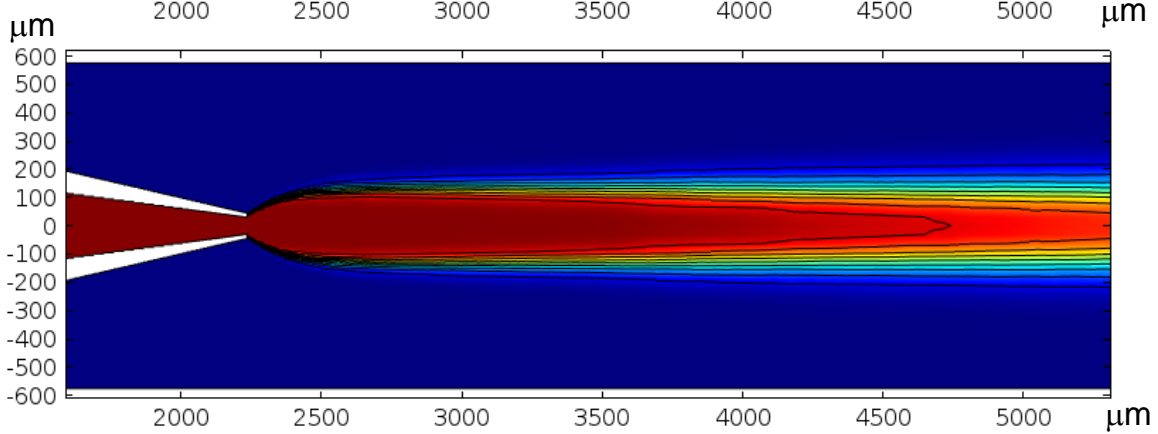

Figure 8. Distribution of mass fraction of THF at: (a) $\boldsymbol{Q}_{a q} / \boldsymbol{Q}_{o r}=\mathbf{1 . 5}, Q_{a q}=5.0 \mathrm{ml} \mathrm{h}^{-1}, Q_{o r}=3.3$ $\mathrm{ml} \mathrm{h}^{-1}$; (b) $\boldsymbol{Q}_{a q} / \boldsymbol{Q}_{o r}=\mathbf{3}, Q_{a q}=5.0 \mathrm{ml} \mathrm{h}^{-1}, Q_{o r}=1.7 \mathrm{ml} \mathrm{h}^{-1}$; (c) $\boldsymbol{Q}_{a q} / \boldsymbol{Q}_{o r}=\mathbf{4 . 5}, Q_{a q}=5.0 \mathrm{ml} \mathrm{h}^{-1}, Q_{o r}$ $=1.1 \mathrm{ml} \mathrm{h}^{-1}$; (d) $\boldsymbol{Q}_{a q} / \boldsymbol{Q}_{o r}=7, Q_{a q}=5.0 \mathrm{ml} \mathrm{h}^{-1}, Q_{o r}=0.7 \mathrm{ml} \mathrm{h}^{-1}$; (e) $\boldsymbol{Q}_{a q} / \boldsymbol{Q}_{o r}=\mathbf{1 0}, Q_{a q}=5.0 \mathrm{ml} \mathrm{h}^{-1}$, $Q_{o r}=0.5 \mathrm{ml} \mathrm{h}^{-1}$. Contours: Mass fractions of THF at 0.1 increment $(0.1,0.2, \ldots ., 0.9)$. Vertical green line is a section considered in Figure 9 (a). 

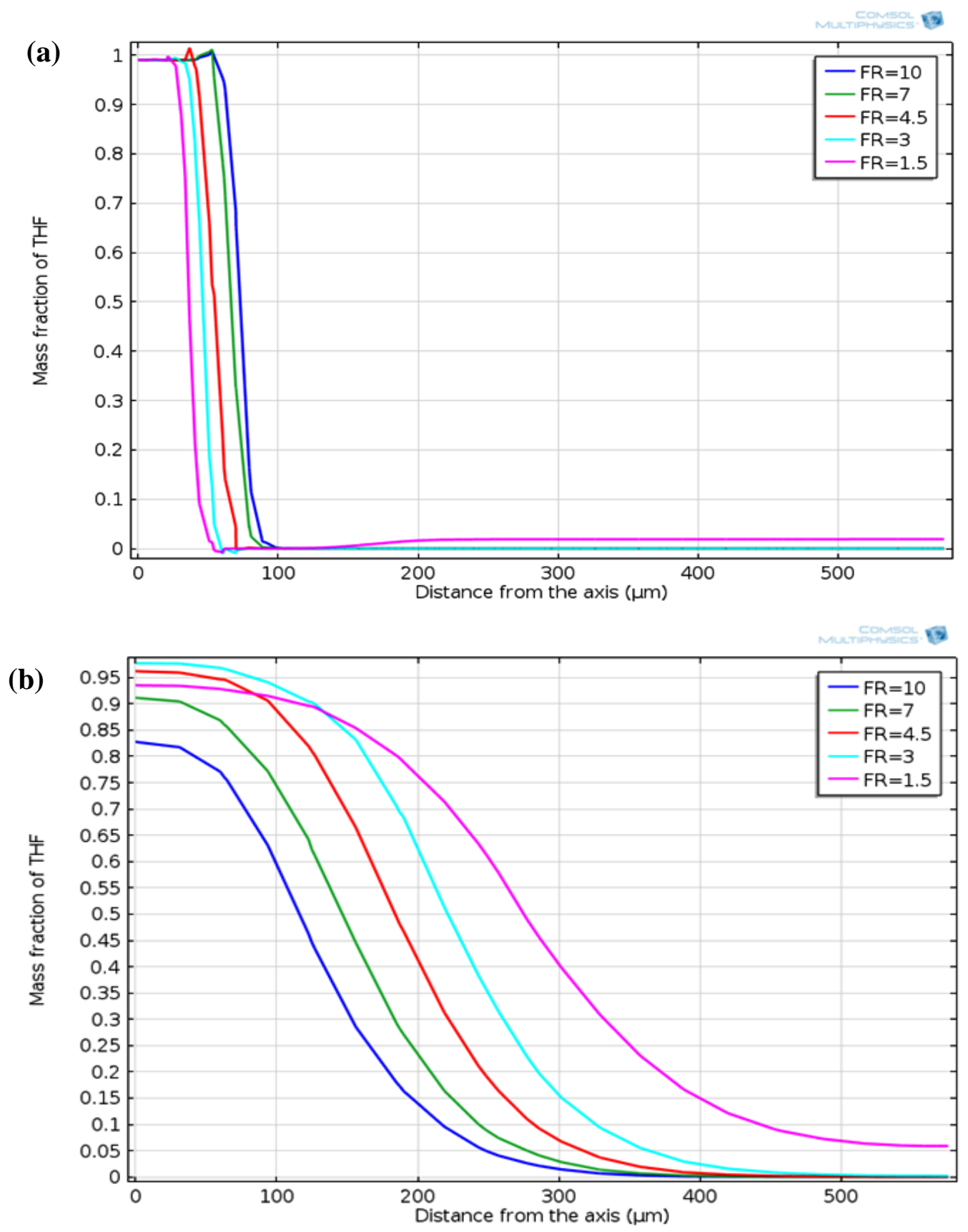

Fig. 9. Profiles of mass fraction of THF for various flow rate ratios $(F R)$ at a cross section located: (a) $D_{N}$ downstream from the nozzle; (b) $5.5 \mathrm{~W}$ downstream from the nozzle $\left(D_{N}=\right.$ internal diameter of the nozzle, $W=$ width of the square capillary, and $\left.F R=Q_{a q} / Q_{o r}\right)$. 
(a)

(b)

(c)

(d)

(e)
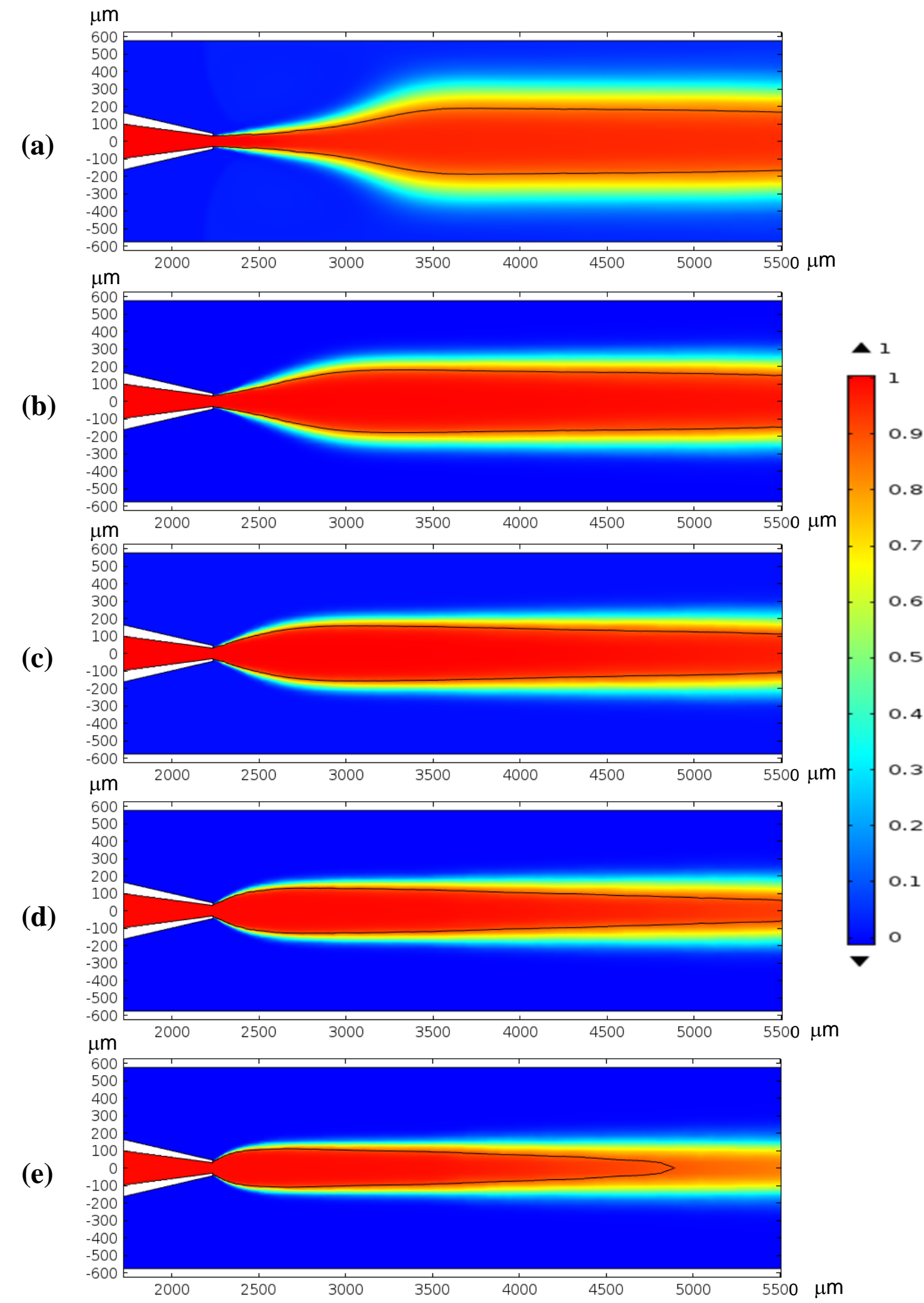

Fig. 10. Distribution of mass fraction of PCL at: (a) $Q_{a q} / Q_{o r}=1.5, Q_{a q}=5.0 \mathrm{ml} \mathrm{h}^{-1}, Q_{o r}=3.3$ $\mathrm{ml} \mathrm{h}^{-1}$; (b) $\boldsymbol{Q}_{a q} / \boldsymbol{Q}_{o r}=\mathbf{3}, Q_{a q}=5.0 \mathrm{ml} \mathrm{h}^{-1}, Q_{o r}=1.7 \mathrm{ml} \mathrm{h}^{-1}$; (c) $\boldsymbol{Q}_{a q} / \boldsymbol{Q}_{o r}=\mathbf{4 . 5}, Q_{a q}=5.0 \mathrm{ml} \mathrm{h}^{-1}$, $Q_{o r}=1.1 \mathrm{ml} \mathrm{h}^{-1}$; (d) $\boldsymbol{Q}_{a q} / \boldsymbol{Q}_{o r}=7, Q_{a q}=5.0 \mathrm{ml} \mathrm{h}^{-1}, Q_{o r}=0.7 \mathrm{ml} \mathrm{h}^{-1}$; (e) $\boldsymbol{Q}_{a q} / \boldsymbol{Q}_{o r}=\mathbf{1 0}, Q_{a q}=5.0$ $\mathrm{ml} \mathrm{h}^{-1}, Q_{o r}=0.5 \mathrm{ml} \mathrm{h}^{-1}$. Black lines: precipitation (cloud point) lines for PCL. 
(a)

(b)

(c)

(d)

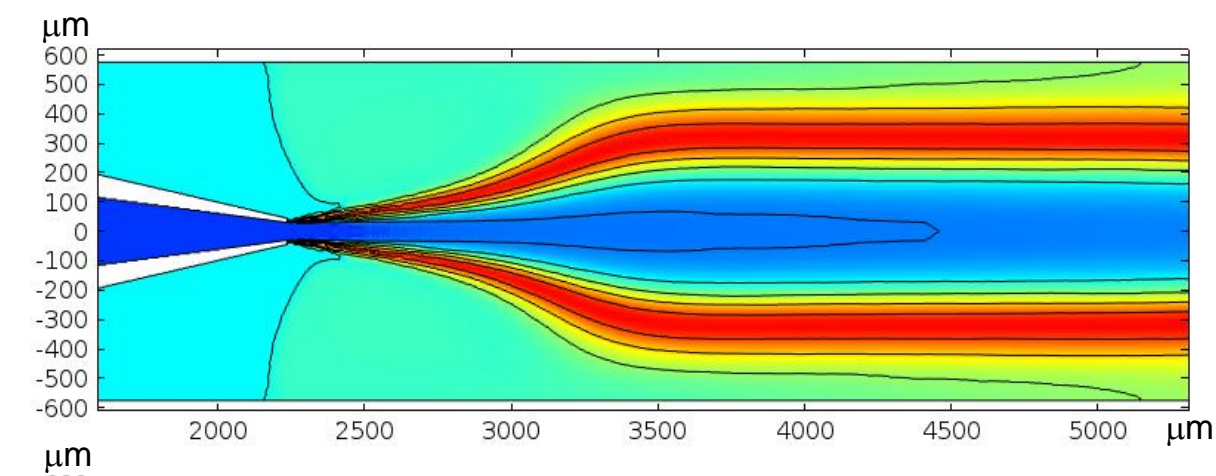

(c)

(b)

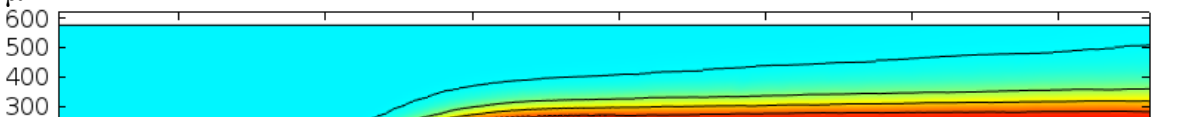

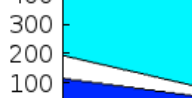
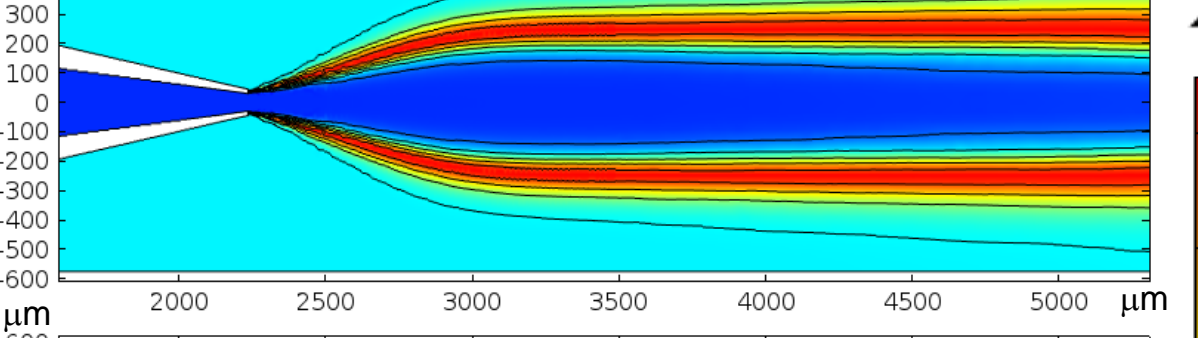

- $\quad 20.9$

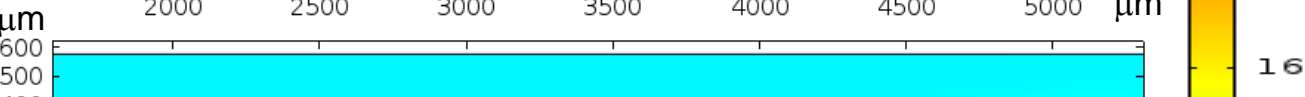

400

300

$200=$

100
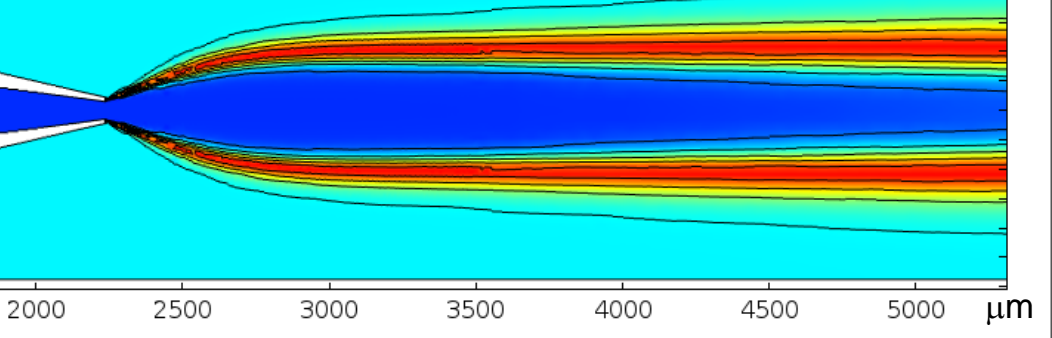

500

\begin{abstract}
(1)
\end{abstract}
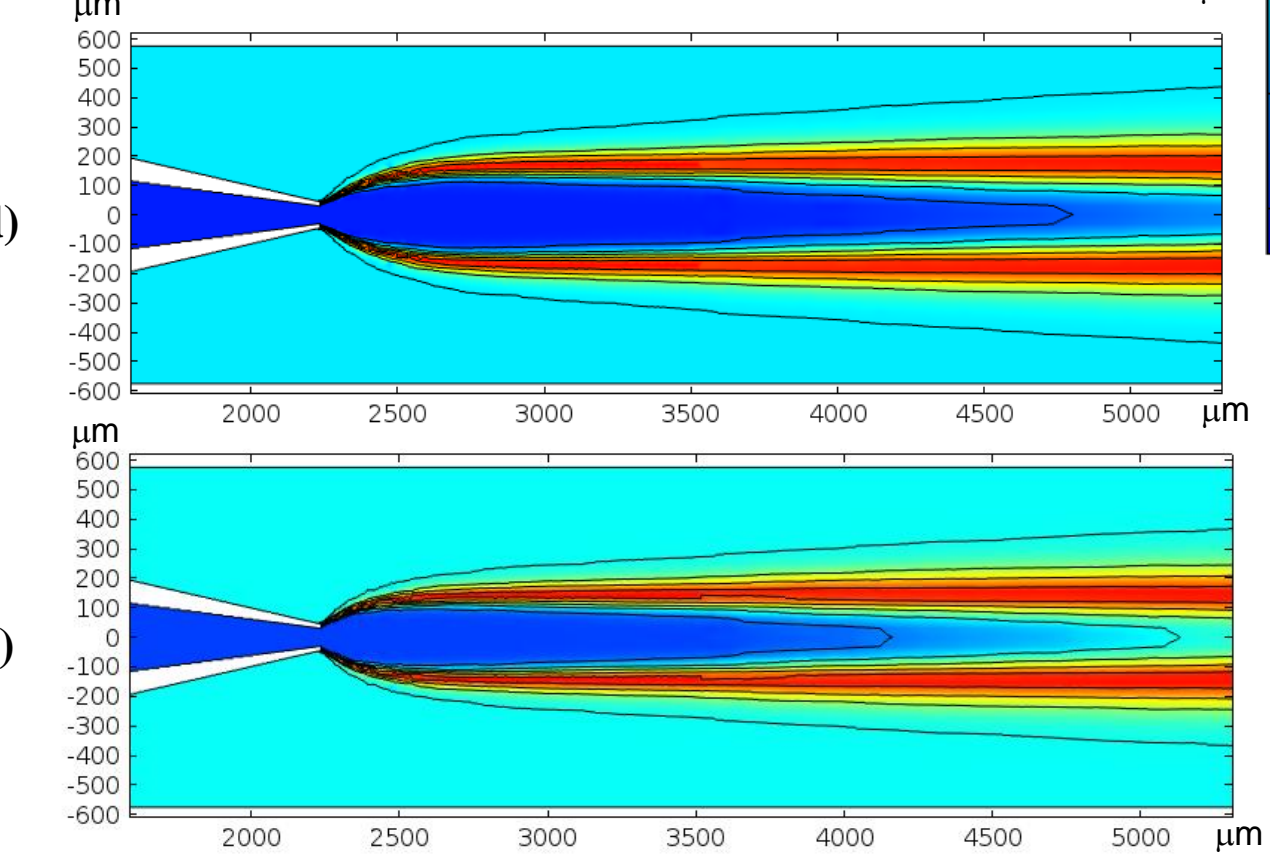

(e)

Fig. 11. Surface and contours of dynamic viscosity (in milipoise) at: (a) $\boldsymbol{Q}_{a q} / \boldsymbol{Q}_{\boldsymbol{o r}}=\mathbf{1 . 5}, Q_{a q}=$ $5.0 \mathrm{ml} \mathrm{h}^{-1}, Q_{o r}=3.3 \mathrm{ml} \mathrm{h}^{-1}$; (b) $Q_{a q} / Q_{o r}=3, Q_{a q}=5.0 \mathrm{ml} \mathrm{h}^{-1}, Q_{o r}=1.7 \mathrm{ml} \mathrm{h}^{-1}$; (c) $\boldsymbol{Q}_{a q} / \boldsymbol{Q}_{o r}=$ 4.5, $Q_{a q}=5.0 \mathrm{ml} \mathrm{h}^{-1}, Q_{o r}=1.1 \mathrm{ml} \mathrm{h}^{-1}$; (d) $Q_{a q} / Q_{o r}=7, Q_{a q}=5.0 \mathrm{ml} \mathrm{h}^{-1}, Q_{o r}=0.7 \mathrm{ml} \mathrm{h}^{-1}$; (e) $\boldsymbol{Q}_{a q} / \boldsymbol{Q}_{o r}=10, Q_{a q}=5.0 \mathrm{ml} \mathrm{h}^{-1}, Q_{o r}=0.5 \mathrm{ml} \mathrm{h}^{-1}$. 

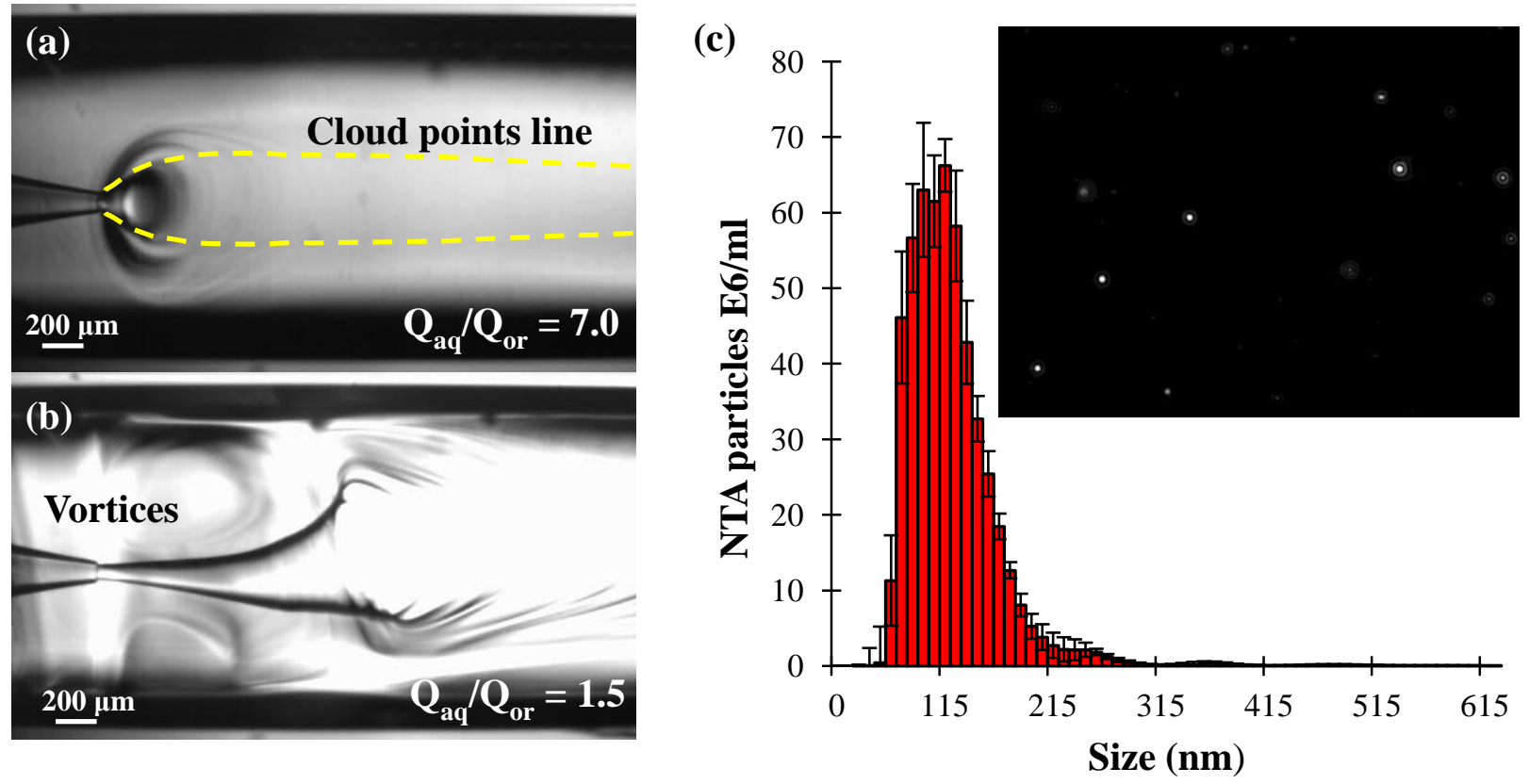

Fig.12. The flow patterns observed in the micromixer at different aqueous to organic phase volume ratios, $Q_{a d} / Q_{o r}:$ (a) 7.0; (b) 1.5 and (c) size distribution from NTA measurement of mixtures of monodisperse PCL nanoparticles with the corresponding video frame at $Q_{a q} / Q_{o r}=$ 10.0. The internal diameter of the nozzle was $60 \mu \mathrm{m}$. 


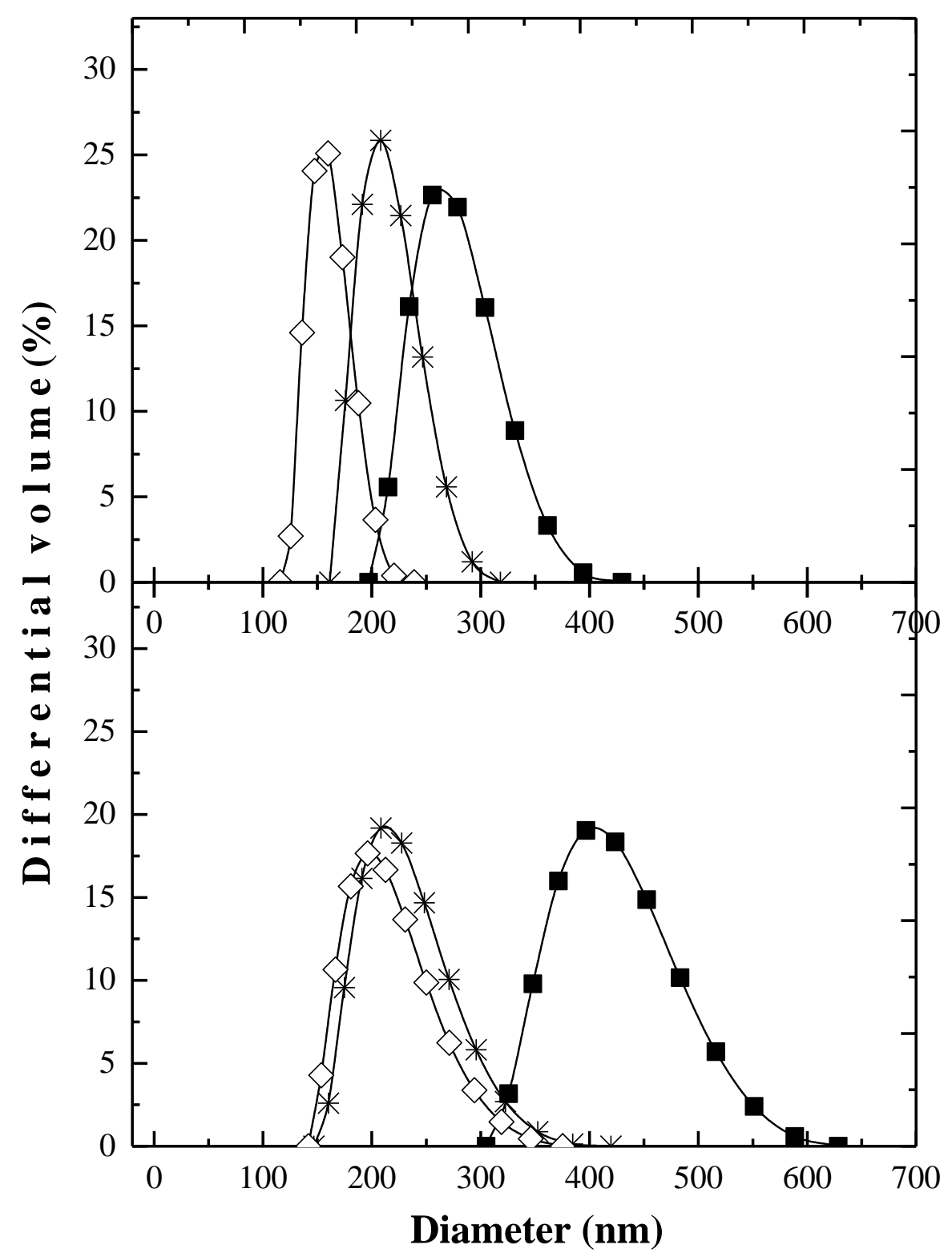

$\longrightarrow Q_{a q} / Q_{o r}=1.5 \multimap Q_{a q} / Q_{o r}=7.0 \smile Q_{a q} / Q_{o r}=10.0$

Fig. 13. Particle size distributions of PCL particles prepared at various flow rate ratios by two different mixing strategies: (a) rapid mixing in co-flow device and (b) bulk mixing. Each measurement was repeated for three times. The internal diameter of the nozzle was $60 \mu \mathrm{m}$. 

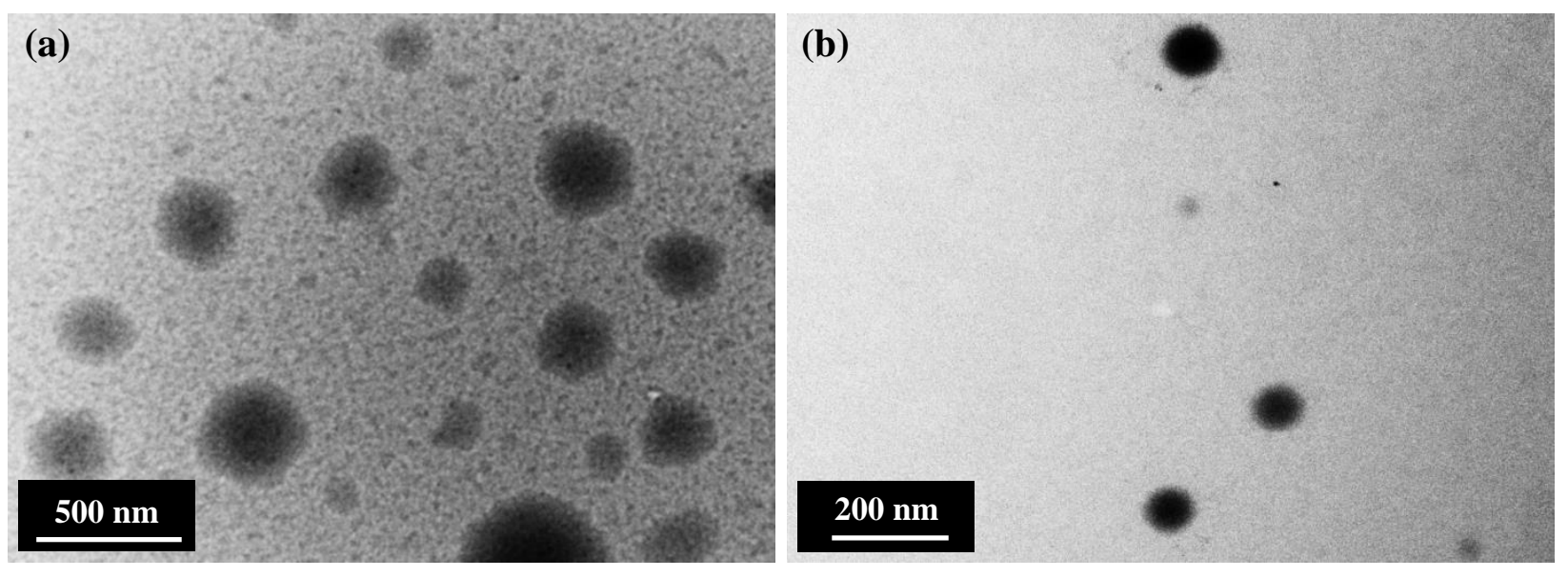

Fig. 14. TEM images of nanoparticles composed of: (a) PCL; (b) PLA. 